NBER WORKING PAPER SERIES

\title{
WHICH INVESTORS MATTER FOR EQUITY VALUATIONS AND EXPECTED RETURNS?
}

\author{
Ralph S. J. Koijen \\ Robert J. Richmond \\ Motohiro Yogo \\ Working Paper 27402 \\ http://www.nber.org/papers/w27402 \\ NATIONAL BUREAU OF ECONOMIC RESEARCH \\ 1050 Massachusetts Avenue \\ Cambridge, MA 02138 \\ June 2020
}

For comments and discussions, we thank John Campbell, Christopher Conlon, Kent Daniel, Xavier Gabaix, Tarek Hassan, Stefan Nagel, Anna Pavlova, Carolin Pflueger, Stijn Van Nieuwerburgh, and conference / seminar participants at Boston College, Chicago Booth, Columbia GSB, University of Hong Kong, Notre Dame, NYU Stern, the 2019 Adam Smith Asset Pricing Conference, the 2019 NBER Long-Term Asset Management Conference, the 2019 NBER Summer Institute International Asset Pricing Conference, the 2019 UCLA Anderson Fink Center Conference on Financial Markets, the 2019 LSE Paul Woolley Center Conference, and the 2020 AFA Meeting. We thank Miguel Ferreira and Pedro Matos for discussions regarding the FactSet data. Ralph Koijen gratefully acknowledges support from the Center for Research in Security Prices. The views expressed herein are those of the authors and do not necessarily reflect the views of the National Bureau of Economic Research.

NBER working papers are circulated for discussion and comment purposes. They have not been peer-reviewed or been subject to the review by the NBER Board of Directors that accompanies official NBER publications.

(C) 2020 by Ralph S. J. Koijen, Robert J. Richmond, and Motohiro Yogo. All rights reserved. Short sections of text, not to exceed two paragraphs, may be quoted without explicit permission provided that full credit, including $\odot$ notice, is given to the source. 
Which Investors Matter for Equity Valuations and Expected Returns?

Ralph S. J. Koijen, Robert J. Richmond, and Motohiro Yogo

NBER Working Paper No. 27402

June 2020

JEL No. G1

\begin{abstract}
$\underline{\text { ABSTRACT }}$
Much work in finance is devoted to identifying characteristics of firms, such as measures of fundamentals and beliefs, that explain differences in asset prices and expected returns. We develop a framework to quantitatively trace the connection between valuations, expected returns, and characteristics back to institutional investors and households. We use it to analyze (i) what information is important to investors in forming their demand beyond prices and (ii) what is the relative importance of different investors-differentiated by type, size, and active share-in the price formation process. We first show that a small set of characteristics explains the majority of variation in a panel of firm-level valuation ratios across countries. We then estimate an asset demand system using investor-level holdings data, allowing for flexible substitution patterns within and across countries. We find that hedge funds and small, active investment advisors are most influential per dollar of assets under management, while long-term investors, such as pension funds and insurance companies are least influential. In terms of pricing characteristics, small, active investment advisors are most important for the pricing of payout policy, cash flows, and the fraction of sales sold abroad. Large, passive investment advisors are most influential in pricing the Lerner index, a measure of markups, and hedge funds for the CAPM beta.
\end{abstract}

Ralph S. J. Koijen

University of Chicago

Booth School of Business

5807 S Woodlawn Ave

Chicago, IL 60637

and NBER

Ralph.koijen@chicagobooth.edu

Robert J. Richmond

Leonard N. Stern School of Business

Kaufman Management Center

44 West Fourth Street, 9-81

New York, NY 10012

rrichmon@stern.nyu.edu
Motohiro Yogo

Department of Economics

Princeton University

Julis Romo Rabinowitz Building

Princeton, NJ 08544

and NBER

myogo@princeton.edu 
Much work in finance is devoted to understanding whether certain stock characteristics are reflected in asset prices. Examples of such characteristics include a firm's fundamentals, measures of beliefs about returns or cash flows, and, more recently, environmental, social, and governance (ESG) measures. ${ }^{1}$ To explain these facts, the literature often provides narratives related to different types of investors whose asset demands reflect these characteristics, such as arbitrageurs or hedge funds in search of mispricings, sentiment-driven retail investors, or pension funds and sovereign wealth funds with sustainability mandates. We develop a framework to quantitatively trace the connection between valuations, expected returns, and characteristics back to specific investors or groups of investors.

Our starting point is the large empirical literature that shows that demand curves for individual stocks slope down (Shleifer 1986). The latest estimates put the estimate around one (Chang, Hong, and Liskovich 2015) - even at longer horizons (Barbon and Gianinazzi 2019). In inelastic financial markets, differences in demand are reflected in asset prices. If demand were instead highly elastic, as implied by many standard models of beliefs and preferences, the demand of a group of investors for a particular stock or characteristic would only have a modest impact on prices, as other investors would quickly substitute from one stock to another.

To develop intuition for our general approach, we start with a simple example. We group institutional investors by type: investment advisors, hedge funds, long-term investors, private banking, and brokers. Investment advisors are further broken down by size and active share,$^{2}$ as this is a large category of institutional investors that includes mutual funds. Long-term investors include pension funds and insurance companies. ${ }^{3}$ The red bars in the top panel of Figure 1 summarize the size distribution across groups.

The first question that we are interested in is how much firm valuations would change if all institutions of a particular type switched to holding a market-weighted portfolio. Understanding how much valuations change in such a scenario quantifies how each type of

\footnotetext{
${ }^{1}$ Prominent examples include La Porta (1996), La Porta et al. (2002), Hong and Kacperczyk (2009), Yermack (1996), Bebchuk, Cohen, and Ferrell (2008), Fillat and Garetto (2015), Giroud and Mueller (2011), and Gompers, Ishii, and Metrick (2003).

${ }^{2}$ We define the active share as the sum of absolute deviations of an investors portfolio from a marketweighted portfolio, based on the same securities as the ones held by the investor, divided by two.

${ }^{3}$ We discuss the construction of the groups in Section III.
} 
institution's deviation from market weights impacts firm valuations. We can use the elasticity estimates from the literature above to get an initial estimate. Given an investor's current holdings, we can compute the shift in demand required for a group of investors to switch to a market portfolio. We then multiply this shift in demand by minus one, assuming a unit elasticity based on Chang, Hong, and Liskovich (2015).

The green bars in the top panel of Figure 1 present our repricing measure under these assumptions. We compute the counterfactual valuations and take the absolute value of the difference with the current valuations. We then normalize it by the total value of the market. Hence, a measure of $10 \%$ implies that $10 \%$ of the market gets repriced. The size of this measure, across institutional types, depends on the size of the sector as well as how far the initial portfolios are from the market-weighted portfolio. The latter component explains the differences between the green and the red bars in Figure 1.

Despite its intuitive appeal, this calculation has three important shortcomings. First, it assumes that the slope of the demand of each stock is the same and equal to one. As stocks are held by different investors with heterogeneous demand elasticities, slopes of demand curves also vary across stocks. Second, the empirical literature has only estimated elasticities, but not the cross elasticities. Hence, we do not know how the price of Apple changes in response to a demand shock for Google. To understand how much a group of investors matters for prices, both elasticities and cross-elasticities are important. Third, using only an investor's active share and a well-identified estimate of the demand elasticity, we cannot assess how much an investor matters to incorporate information about specific characteristics into prices - only its overall impact. The methodology that we develop in this paper is designed to solve all three shortcomings.

To develop intuition for our empirical strategy, we start with a simple model in which investors use a set of characteristics to forecast a firm's future profitability and to assess its riskiness. The demand curve of investors can be expressed as a function of prices and characteristics. Investors may disagree, and may have incorrect beliefs, about which or how much characteristics are relevant for future profits and their riskiness. In equilibrium, prices depend on characteristics, as in cross-sectional valuation regressions. The coefficients on the characteristics are a weighted average of the preferences of the investors, where the weights 
Figure 1

Total Repricing By Institution Type (US)

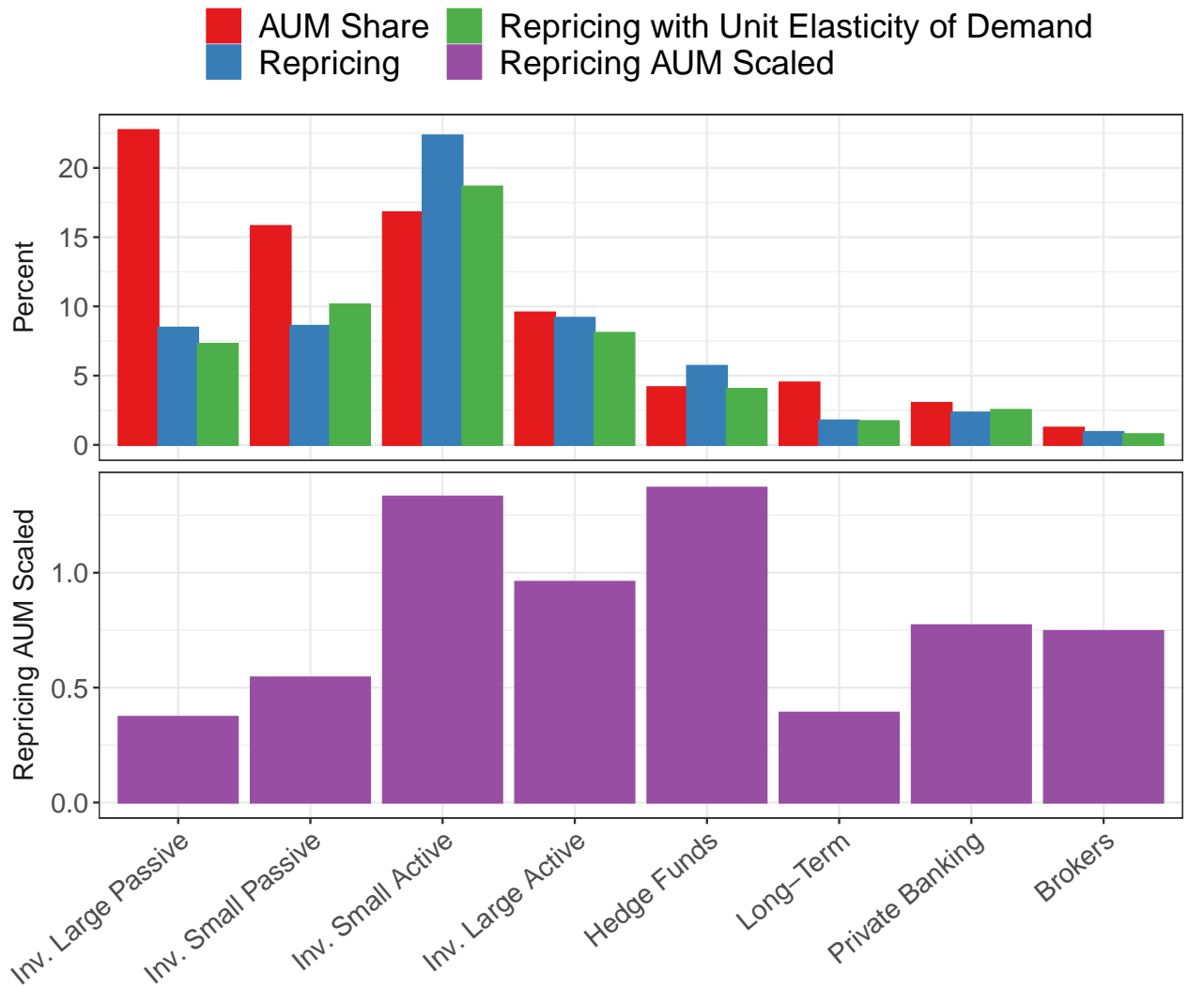

The top panel reports the fraction of assets under management, repricing, and repricing assuming that the elasticity of demand is one. Repricing is the percent change in market cap if an investor type's demand curve changes to strict market weights. Repricing with unit elasticity of demand is the percent change in market cap if an investor type's demand curve changes to strict market weights and assuming that the elasticity of demand is equal to one. The bottom panel reports the change in market cap normalized by the fraction of ownership. Each bar is the time series average of the yearly values. The bottom panel reports the change in market cap normalized by the fraction of ownership. Each bar is the time series average of the yearly values. Firm-level fundamentals and equity holdings data are from FactSet from 2006 until 2016. 
depend on assets under management.

The model guides our empirical analysis. First, we use firm characteristics to explain the cross-sectional variation in valuation ratios. A large literature studies how variation in these valuation ratios relates to expected returns and firm performance (e.g. Fama and French (1995), Daniel and Titman (2006), and Campbell, Polk, and Vuolteenaho (2009)). We show that a small set of six characteristics related to risk, productivity, and profitability explains the majority of variation in a panel of valuation ratios in the United States (US), Great Britain (GB), the Euro area, and Japan. The residual variation in valuation ratios could be due to other factors such as fluctuations in sentiment (Barberis, Shleifer, and Vishny 1998), funding constraints and other institutional frictions (Brunnermeier and Pedersen 2009), or potentially unobserved characteristics. We also show that the same characteristics predict about a third of the variation in firms' future profit growth in each of the regions.

In our main empirical analysis, we estimate an international asset demand system in which investors' demands are modeled as a function of prices, characteristics, and latent demand, which captures unobserved components of demand. By imposing market clearing, we can solve for equilibrium asset prices.

We estimate the model using data in GB and in the US from 2006 to 2016. The model allows for flexible substitution patterns across stocks within and across countries, and we allow for rich heterogeneity across investors. A salient fact revealed by our estimates of investors' demand curves is that the portfolios of institutional investors, both within and across groups (e.g., hedge funds, mutual funds, broker dealers, ...), deviate significantly from market weights.

With the demand curve estimates in hand, we ask the same question as before and measure how much valuations change if a group of investors switches to a market-weighted portfolio. The blue bars in Figure 1 summarize the results. While the green and blue bars are positively correlated, there are substantial differences. This illustrates the importance of heterogeneity in the demand elasticities across investors and the cross-elasticities that the simple calculation ignored.

As discussed before, part of differences in the repricing measure across groups is driven by their size, as measured by assets under management. Therefore, we also compute the 
repricing measure scaled by the total assets managed by a particular group. The results are presented in the bottom panel of Figure 1. Per dollar of assets managed, hedge funds and small, active investment advisors have the largest impact on valuations, with a ratio of repricing to AUM share of over 1.25. On the other end of the spectrum, we find that large, passive investment advisors and long-term investors, such as pension funds and insurance companies, have a relatively small impact on valuations with a ratio below 0.5.

We also explore the link to investors' size in detail. Investors' active share is inversely related to size, as is well known. When splitting institutions into five groups of equal size by AUM, the repricing measure is inversely related to size — both in absolute terms and when scaled by assets under management. We find that small, active investment advisors and hedge funds are the most price elastic institutional investors. This implies that when those institutions switch to holding a market indexing strategy, prices need to move more to change the portfolios of, for instance, large, passive investors. Combined with the fact that the small institutions are more active as well, their impact on prices is larger.

To understand how much different investors matter in connecting asset prices to firm characteristics, we re-estimate valuation regressions in each country using the counterfactual prices and document how the coefficients of cross-sectional valuation regression, and their residuals, change.

To summarize the results, we compute changes in the coefficients of the valuation regressions. As discussed before, we consider six characteristics. The first characteristic is log book equity, which captures size effects. To forecast future productivity and profitability, we use the sales-to-book equity ratio, the foreign sales share, the dividend-to-book equity ratio, and the Lerner index. Our use of the foreign sales share is motivated by models such as Melitz (2003) in which only the most productive firms export to other countries. The Lerner index is a simple measure of markups that is also used in the recent literature on industry concentration and the rise of superstar firms (see for instance Guitierrez and Philippon (2017) and Autor et al. (2020)). Lastly, we include a stock's market beta as the canonical measure of stock market risk.

Small, active investment advisors are most important for the pricing of foreign sales. If these investors would hold a market-weighted strategy instead of their current strategy, the 
coefficient of valuation ratios on the fraction of sales that is exported would decline by more than $10 \%$. These investors therefore play an important role in determining the cost of capital of global firms.

Small, active investment advisors are also most influential to price cash flows, payout policy, and firm size. The coefficients on these characteristics in valuation regressions would change by $19 \%, 64 \%$, and $64 \%$, respectively. For the Lerner index, large, passive investment advisors are most important (an impact of $23.0 \%$ ).

Lastly, hedge funds are most influential in pricing market beta (an impact of -34\%). Hedge funds are generally quite important, as their impact on the coefficient of the Lerner index is $20 \%, 23 \%$ for dividend-to-book, $11 \%$ for firm size, and $8 \%$ for the foreign sales share. As discussed before, the influence of hedge funds is remarkable given their relatively small size.

Taken together, these results show how important different investors are for the pricing of characteristics and the same calculations can be done for other characteristics, such as governance or environmental scores, in future applications of our framework as environmental and social concerns become more important.

Combined with a forecasting model for expected future growth rates, this also measures the importance of each investor type in connecting characteristics to long-horizon expected returns using the present-value identities developed in Campbell and Shiller (1988) and Vuolteenaho (2002). Our results on prices conditional of characteristics, show again that hedge funds appear to be especially important to incorporate information into prices, conditional on their size.

We build on Koijen and Yogo (2019), who developed a framework for estimating demand curves of institutional investors and households. Our first contribution is to develop a framework to quantitatively trace the connection between valuations, expected returns, and characteristics back to institutional investors and households. Second, we use new data on institutional types which, in particular, identifies hedge funds who play an important role in the analysis. The new holdings data also covers two countries. Third, we develop a new methodology to estimate demand curves. As many institutions hold relatively concentrated portfolios, earlier literature pools the holdings of investors to gain precision. We develop an 
instrumental variables shrinkage estimator that also accounts for the zeros when investors choose not to hold a given stock. The degree of shrinkage depends on the number of stocks held by an investor and vanishes asymptotically. Overall, our approach ensures that we allow for maximum heterogeneity in demand curves across investors and highlights substantial differences in the demand of and importance of different institutional investors.

\section{Which investors matter for asset prices? Theory}

We present a simple model to illustrate how we can measure the importance of various investors in the price formation process. While the model is intentionally stylized, the basic economic insights extend to many asset pricing models, and the model motivates the empirical strategy that we follow in subsequent sections. We summarize the main assumptions and results, and provide further derivations in Appendix B.

Assumptions about beliefs, preferences, and technology We consider a two-period model with time indexed by $t=0,1$. There are $N$ assets indexed by $n=1, \ldots, N$ and $I$ investors indexed by $i=1, \ldots, I$. The supply of each asset is normalized to one. Vectors and matrices are denoted in bold. Elements of vectors are indexed with parentheses.

Investors have constant absolute risk aversion (CARA) preferences over assets at time 1,

$$
\max _{\mathbf{q}_{i}} \mathbb{E}\left[-\exp \left(-\gamma_{i} A_{1 i}+Y_{1 i}\right)\right]
$$

where $\mathbf{q}_{i}$ is a vector of asset holdings expressed in terms of the number of shares held. $Y_{1 i}$ represents other risk factors that impact the investor such as benchmarking, outside income, time-varying investment opportunities, et cetera.

The optimization is subject to the intra-period budget constraint

$$
A_{0 i}=\boldsymbol{q}_{i}^{\prime} \boldsymbol{P}_{0}+Q_{i}^{0}
$$

where $\boldsymbol{P}_{0}$ denotes the vector of asset prices and $Q_{i}^{0}$ the dollar investment in a cash account. The cash account has a price normalized to one and earns a rate of interest that we normalize 
to zero. We parameterize the cross-sectional distribution of absolute risk aversion coefficients as $\gamma_{i}=\left(\tau_{i} A_{i 0}\right)^{-1} \cdot{ }^{4}$

The terminal payoffs of firms are denoted by $\boldsymbol{D}_{1}$ and their book equity values by $\boldsymbol{B}_{0}$. We define the return on equity (ROE) for firm $n$ as $d_{1}(n)=D_{1}(n) B_{0}^{-1}(n)$. We assume that all investors agree that ROEs follow a factor model,

$$
\mathbf{d}_{1}=\boldsymbol{g}_{i}+\boldsymbol{\rho}_{i} F_{1}+\boldsymbol{\eta}_{1}
$$

where $\operatorname{Var}\left(\boldsymbol{\eta}_{1}\right)=\sigma^{2} \boldsymbol{I}, \boldsymbol{\eta}_{1}$ and $F_{1}$ are independent, normally distributed with mean zero, and we normalize $\operatorname{Var}\left(F_{1}\right)=1$. Investors may disagree on the systematic exposure of stocks to the factor, $\boldsymbol{\rho}_{i}$. In addition, investors may disagree about the expected growth rate, $\boldsymbol{g}_{i}$. We assume that investors have full information about other investors' beliefs and agree to disagree - they do not revise their beliefs based on asset prices.

In order to estimate the expected growth rate and the riskiness of the firm's future profits, investors rely on public information, "characteristics," $\boldsymbol{x}$, and potentially other information, as captured by $\nu^{g}$ and $\nu^{\rho}$,

$$
\begin{aligned}
& g_{i}(n)=\boldsymbol{\lambda}_{i}^{g \prime} \boldsymbol{x}(n)+\nu_{i}^{g}(n), \\
& \rho_{i}(n)=\boldsymbol{\lambda}_{i}^{\rho \prime} \boldsymbol{x}(n)+\nu_{i}^{\rho}(n),
\end{aligned}
$$

where $\nu_{i}^{g}$ and $\nu_{i}^{\rho}$ are assumed to be uncorrelated with $\boldsymbol{x}$. The first element of $\boldsymbol{x}$ equals book equity, to capture size differences across firms, and $\boldsymbol{x}$ also includes a constant.

We formulate the budget constraint as

$$
A_{1 i}=A_{0 i}+\boldsymbol{Q}_{i}^{\prime}\left(\boldsymbol{d}_{1}-\boldsymbol{M} \boldsymbol{B}_{0}\right)
$$

where $M B_{0}(n)=P_{0}(n) B_{0}^{-1}(n)$, a firm's market-to-book ratio, and $Q_{i}(n)=B_{0}(n) q_{i}(n)$. We refer to $\boldsymbol{g}_{i}-\boldsymbol{M} \boldsymbol{B}_{0}$ as (long-horizon) expected returns.

To complete the model, we assume the background risk factor $Y_{1 i}$ is normally distributed,

\footnotetext{
${ }^{4}$ For this particular choice, the model's implications mimic those of a more standard constant relative risk aversion (CRRA) utility model, while maintaining the tractability of the CARA-normal model. Our modeling strategy follows Makarov and Schornick (2010).
} 
$Y_{1 i} \sim N\left(\mu_{Y i}, \sigma_{Y i}^{2}\right)$, and

$$
2 \operatorname{Cov}_{i}\left(Y_{1 i}, d_{1}(n)\right)=y_{i}(n)=\boldsymbol{\lambda}_{i}^{Y \prime} \boldsymbol{x}(n)+\nu_{i}^{Y}(n),
$$

where $\operatorname{Cov}_{i}(V, W)$ denotes the covariance between $V$ and $W$ according to investor $i$ 's beliefs.

Model solution We solve the model in Appendix B and summarize the main results here. Investor $i$ 's optimal demand is given by

$\boldsymbol{Q}_{i}(n)=-\underbrace{\frac{1}{\gamma_{i} \sigma^{2}}}_{\beta_{0 i}} \boldsymbol{M} \boldsymbol{B}_{0}(n)+\frac{1}{\gamma_{i} \sigma^{2}} \underbrace{\left(\boldsymbol{\lambda}_{i}^{g}-c_{i} \boldsymbol{\lambda}_{i}^{\rho}+\boldsymbol{\lambda}_{i}^{Y}\right)^{\prime}}_{\boldsymbol{\beta}_{1 i}} \boldsymbol{x}(n)+\frac{1}{\gamma_{i} \sigma^{2}} \underbrace{\left(\nu_{i}^{g}(n)-c_{i} \nu_{i}^{\beta}(n)+\nu_{i}^{Y}(n)\right)}_{\epsilon_{i}(n)}$,

where $c_{i}$ is a scalar that does not vary across securities. Empirically, we can link portfolio holdings to observable characteristics. However, this expression shows that we cannot tell whether investors attend to a particular characteristic because they view this information as being relevant in forecasting future profits, to assess or hedge risk, or both. Likewise, if an investor deviates from her demand curve conditional on characteristics, which is the last term in (7), we cannot tell whether this is due to a particular view on expected growth rates, risk or hedging benefits.

By imposing market clearing, $\sum_{i} \boldsymbol{Q}_{i}=\boldsymbol{B}$, we can solve for equilibrium market-to-book ratios,

$$
M B(n)=\overline{\boldsymbol{\beta}}_{m b}^{\prime} \boldsymbol{x}(n)+\bar{\epsilon}_{m b}(n),
$$

where $m_{i}=\left(\tau_{i} A_{i}\right)\left(\sum_{j} \tau_{j} A_{j}\right)^{-1}, \overline{\boldsymbol{\beta}}_{m b}=\sum_{i} m_{i} \boldsymbol{\beta}_{1 i}-\frac{\sigma^{2}}{\sum_{i} \tau_{i} A_{i}} \boldsymbol{e}_{1}$, with $\boldsymbol{e}_{1}$ the first unit vector, ${ }^{5}$ and $\bar{\epsilon}_{m b}(n)=\sum_{i} m_{i} \epsilon_{i}(n)$.

Hence, valuation ratios are connected to characteristics since investors view those characteristics as being relevant to assess risk (via $\boldsymbol{\lambda}_{i}^{\rho}$ ), to forecast future profitability (via $\boldsymbol{\lambda}_{i}^{g}$ ), or for hedging purposes (via $\boldsymbol{\lambda}_{i}^{Y}$ ). Large investors and investors with more extreme views affect prices more and are therefore more important in the price formation process.

\footnotetext{
${ }^{5}$ Recall that we ordered the characteristics in such a way that book equity is the first characteristic.
} 
The first element of $\overline{\boldsymbol{\beta}}_{m b}$ has two terms, $\sum_{i} m_{i} \boldsymbol{\beta}_{1 i}(1)-\frac{\sigma^{2}}{\sum_{i} \tau_{i} A_{i}}$. The first term, like for all other characteristics, captures how investors use log book equity to forecast a firm's future growth and to assess its riskiness. The second term reflects the fact that larger firms expose investors to more idiosyncratic risk, which, all else equal, leads to lower valuation ratios. Depending on the slope of the demand curve for individual stocks, we expect log book equity to enter cross-sectional valuation regressions with a negative sign, and this effect to be more pronounced if stock-level demand is more inelastic.

The contribution of investors to the price formation process We explain how we quantify the importance of an investor, or group of investors, in the price formation process. We consider the case in which an investor $j$ switches to strict market weights, that is, $\boldsymbol{q}_{j}=\theta_{j} \boldsymbol{\iota}$, where $\theta_{j}$ is chosen to satisfy the investor's budget constraint. Using this demand curve for investor $j$, the market clearing condition changes to

$$
\sum_{i, i \neq j} \boldsymbol{Q}_{i}+\theta_{j} \boldsymbol{B}=\boldsymbol{B}
$$

that is, $\sum_{i, i \neq j} \boldsymbol{q}_{i}=\left(1-\theta_{j}\right) \boldsymbol{B}$. The new market-clearing valuation ratio is

$$
M B_{0, j}^{C F}(n)=\boldsymbol{\lambda}_{m b}^{-j \prime} \boldsymbol{x}(n)+\epsilon_{m b}^{-j}(n),
$$

where $\boldsymbol{\lambda}_{m b}^{-j}=\left(1-\theta_{j}\right)^{-1}\left(\sum_{i, i \neq j} A_{i} \tau_{i} \boldsymbol{\beta}_{1 i}-\sigma^{2} \boldsymbol{e}_{1}\right)\left(\sum_{i, i \neq j} A_{i} \tau_{i}\right)^{-1}$ and analogously for $\epsilon_{m b}^{-j}(n)$. Hence, the assets are now priced according to the weighted average demand curve of all other investors. Indeed, implementing a passive market indexing strategy is equivalent to assigning investor $j$ the weighted demand curve of all other investors. The weights are proportional to $A_{i} \tau_{i}$, the size-weighted risk tolerance.

By comparing $\boldsymbol{\lambda}_{m b}^{-j}$ to $\boldsymbol{\lambda}_{m b}$, we measure the importance of investor $j$ to incorporate a firm's characteristics into prices. Likewise, by comparing $\epsilon_{m b}^{-j}$ to $\epsilon_{m b}$, we measure how important investor $j$ is in explaining the residual in cross-sectional valuation regressions, and hence which investors cause a stock to be a value or a growth stock. The valuation impact of a given investor depends on its size, the slope of the residual demand curve, and how different an investor's demand curve is from other investors. 
Lastly, we define $\boldsymbol{g}_{R}(\boldsymbol{x})-\boldsymbol{M} \boldsymbol{B}_{0}$ as our measure of long-horizon expected returns, where $\boldsymbol{g}_{R}$ is the rational expectations forecast of $\boldsymbol{d}_{1}$ conditional on characteristics $\boldsymbol{x}, \boldsymbol{g}_{R}(\boldsymbol{x}) \equiv \mathbb{E}\left[\boldsymbol{d}_{1} \mid \boldsymbol{x}\right]$. We can therefore also compute the impact of investor $j$ on expected returns by comparing $\boldsymbol{g}_{R}(\boldsymbol{x})-\boldsymbol{M} \boldsymbol{B}_{0}$ to $\boldsymbol{g}_{R}(\boldsymbol{x})-\boldsymbol{M} \boldsymbol{B}_{0, j}^{C F}$. In addition, we can measure how much investor $j$ matters for the relation between long-horizon expected returns and the characteristics, $\boldsymbol{x}{ }^{6}$

\section{An empirically-tractable model of the asset demand system}

Building on the insights in the previous section, we now develop an empirically-tractable asset demand system, which allows for rich heterogeneity in demand curves across investors. Our model extends the asset demand system in Koijen and Yogo (2019) by allowing for substitution across countries.

\section{A. Notation}

There are $N_{c}$ assets, indexed by $n=1, \ldots, N_{c}$, in country $c$. Lowercase letters denote the logarithm of the corresponding uppercase variables. As before, we denote the characteristics of asset $n$ in period $t$ as $\boldsymbol{x}_{t}(n)$. The financial assets are held by $I$ investors, indexed by $i=1, \ldots, I$. One of the investors in each country is a household sector, which holds whatever assets are not held by institutional investors in that country.

\section{B. The universe of assets and asset demand}

We show in Section III that financial markets are highly concentrated. We therefore use the top $90 \%$ of stocks by market capitalization in each country as the universe of assets. This ensures that our model focuses on pricing the largest firms that capture almost all economic activity among listed firms, and that our estimates are not driven by a large number of small and micro-cap firms. We refer to stocks within an investor's choice set as inside assets. There is an outside asset in each country. We define the outside asset in a given country as all stocks that are not part of the top $90 \%$ and it is indexed by 0 in each country.

\footnotetext{
${ }^{6}$ This calculation is accurate under the assumption that $\boldsymbol{g}_{R}(\boldsymbol{x})$ does not change in the counterfactual, that is, that there are no real effects of investors switching to passive strategies. To relax this assumption, we would need to allow for corporate decisions regarding capital structure, investment, and payout policy. While this is an interesting extension to explore in future work, it is beyond the scope of this paper.
} 
Each investor allocates assets $A_{i, t}$ in period $t$ across assets in its choice sets $\mathcal{N}_{i, c, t} \subseteq$ $\{1, \ldots, N\}$. An investor's choice set is a subset of assets that the investor considers or is allowed to hold. Restrictions on the choice set may be driven by investment mandates, benchmarking or information frictions that limit an investor's ability to analyze a large universe of stocks (Merton 1987). An investor's universe is the set of stocks that the investor holds at some point in our sample from 2006 to 2016, that is $\mathcal{N}_{i, c}=\cup_{t=1}^{T} \mathcal{N}_{i, c, t}$. We denote the number of assets in the investment universe of country $c$ as $\left|\mathcal{N}_{i, c}\right|$.

Investors may invest in GB and the US, and can substitute across countries. Without loss of generality, the portfolio weight of investor $i$ in stock $n$ and country $c$ is

$$
w_{i, t}(n, c)=w_{i, t}(n \mid c) w_{i, t}(c)
$$

The first term on the right side, $w_{i, t}(n \mid c)$, is the portfolio weight across stocks in a given country. The second term, $w_{i, t}(c)$, is the portfolio weight across countries. We next discuss the modeling choices we make for $w_{i, t}(n \mid c)$ and $w_{i, t}(c)$, which are guided by the idea that demand elasticities within and across countries may be different.

The portfolio weight on stock $n$ within country $c$ is

$$
w_{i, t}(n \mid c)=\frac{\delta_{i, t}(n \mid c)}{1+\sum_{m \in \mathcal{N}_{i, c}} \delta_{i, t}(m \mid c)}
$$

where

$$
\delta_{i, t}(n \mid c)=\exp \left\{b_{0, i, c, t}+\beta_{0, i, c} m b_{t}(n)+\boldsymbol{\beta}_{1, i, c}^{\prime} \boldsymbol{x}_{t}(n)\right\} \epsilon_{i, c, t}(n)
$$

and $b_{0, i, c, t}$ are investor-country-time fixed effects. An investor's demand depends on the log market-to-book ratio, firm characteristics, and latent demand, $\epsilon_{i, c, t}(n)$. Latent demand captures investor $i$ 's demand beyond characteristics. Zero holdings, within an investor's choice set, correspond to $\epsilon_{i, c, t}(n)=0$.

This demand curve is motivated by the simple model in Section I, but is empirically more realistic as portfolio holdings are log-normally distributed. We normalize the mean of latent demand $\epsilon_{i, c, t}(n)$ to one so that the intercept $b_{0, i, c, t}$ in equation (11) is identified. This implies 
that the error terms averages to one for a given investor across stocks in each year, but the error terms do not necessarily average to one across investors for a given stock. Indeed, the residual variation in market-to-book ratios beyond characteristics is due to latent demand, see equation (8).

To specify the allocation across countries, $w_{i, t}(c)$, we define $\zeta_{i, t}(c)=1+\sum_{m \in \mathcal{N}_{i, t}} \delta_{i, t}(m \mid c)$, which is the inverse of the fraction invested in the outside asset, $\zeta_{i, t}(c)=\frac{1}{w_{i, t}(0 \mid c)}$. Intuitively, when $\zeta_{i, t}(c)$ is large, inside assets are relatively attractive to investor $i$, compared to the outside asset, in country $c$. This happens when an investor considers the prices to be low relative to fundamentals and latent demand. In this case, the investor may also want to reallocate assets from the foreign country to country $c$.

Following this intuition, we model the portfolio weight of country $c$ as

$$
w_{i, t}(c)=\frac{\zeta_{i, t}(c)^{\psi_{1, i}} \delta_{i, t}(c)}{\zeta_{i, t}(U S)^{\psi_{1, i}} \delta_{i, t}(U S)+\zeta_{i, t}(U K)^{\psi_{1, i}}},
$$

where

$$
\ln \delta_{i, t}(U S)=\psi_{0, i}+\epsilon_{i, t}^{\psi},
$$

and $\delta_{i, t}(U K)=1$, which is a normalization. The model in (12) implies that the country weight is increasing in $\zeta_{i, t}(c)$, that is, the relative attractiveness of inside assets in country c. Our model of portfolio weights is a nested logit model.

It is useful to consider two special cases to develop some intuition. When $\psi_{1, i}=1$, the model collapses to a standard logit model,

$$
w_{i, t}(n, c)=\frac{\delta_{i, t}(n \mid c) \delta_{i, t}(c)}{\sum_{k=1}^{2} \sum_{m=0}^{N} \delta_{i, t}(m \mid k) \delta_{i, t}(k)},
$$

and the elasticity of substitution within and across countries is identical. This implies that the equity markets in GB and the US are perfectly integrated. 
When $\psi_{1, i}=0$,

$$
w_{i, t}(n, c)=\frac{\delta_{i, t}(n \mid c)}{\sum_{m=0}^{N} \delta_{i, t}(m \mid c)} \frac{\delta_{i, t}(c)}{\sum_{k=1}^{2} \delta_{i, t}(k)}
$$

the allocation across asset classes depends only on $\psi_{0, i}+\epsilon_{i, t}^{\psi}$. In this case, the equity markets in both countries are segmented and the relative allocation does not respond to prices, characteristics or latent demand in either country. Empirically, we expect the willingness of investors to substitute within a country to be higher than across countries, and we therefore expect $\psi_{1, i} \in(0,1){ }^{7}$

\section{C. $\quad$ Market clearing}

Portfolio weights sum to one within each region, $\sum_{n \in \mathcal{N}_{i, c}} w_{i, t}(n \mid c)=1$. Additionally, aggregate portfolio weights across regions sum to one, $\sum_{c} w_{i, t}(c)=1$. We define the total investment in the outside assets across regions as $O_{i, t}=\sum_{c} A_{i, t} w_{i, t}(0, c)$. Then investor $i$ 's total assets are given by

$$
A_{i t}=\frac{O_{i, t}}{1-\sum_{c} \sum_{n=0}^{N} w_{i, t}(n, c)} .
$$

We complete the model with the market clearing condition for each asset $n$ in country $c$

$$
\begin{aligned}
M E_{t}(n, c) & =\sum_{i=1}^{I} A_{i, t} w_{i, t}(n, c) \\
& =\sum_{i=1}^{I} \frac{O_{i, t} w_{i, t}(n, c)}{1-\sum_{c} \sum_{n=0}^{N} \cdot w_{i, t}(n, c)} .
\end{aligned}
$$

The market value of shares outstanding must equal the asset-weighted sum of portfolio weights across all investors. In solving for equilibrium asset prices, we follow the literature on asset pricing in endowment economies (Lucas 1978) and assume that shares outstanding and the characteristics are exogenous. Additionally, we assume that investor's holdings of outside assets are exogenous.

\footnotetext{
${ }^{7}$ Theoretically, there is no upper-bound on $\psi_{1 i}$ and values above one would imply that investors are more willing to substitute across countries compared to within countries.
} 
Koijen and Yogo (2019) show that $\beta_{0, i, c}<1$, for all investors and in each country, is a sufficient condition for both individual and aggregate demand to be downward sloping. We impose this condition in estimating the demand system.

\section{Data and stylized facts}

\section{A. Data}

The data on firm characteristics, stock prices, and portfolio holdings are from FactSet. The details on the data construction can be found in Appendix A. While FactSet provides holdings data in many countries, the types of institutions covered varies due to differences in reporting requirements across countries. As a result, we have only mutual fund holdings for a large number of countries, which is insufficient for the purposes of this paper.

For the holdings data, we therefore restrict attention to GB and the US. The US holdings data are sourced from 13-F reports and reports to FactSet by individual funds. The GB holdings data are sourced from the UK Share Register (UKSR) in combination with fund holdings. We follow the FactSet methodology, as detailed in the appendix, to combine various sources. We aggregate the holdings to the institutional level by country.

We check the coverage of the data in Figure A.1. We plot the total holdings of US firms by UK investors and vice versa using the FactSet data. As a point of reference, we use the IMF's Coordinated Portfolio Investment Survey (CPIS). As the figure illustrates, the FactSet data are highly representative of aggregate cross-border holdings and closely match the figures from the CPIS.

We group investors into eight groups. First, we group investors by type: Investment Advisors, Long-Term Investors, Hedge Funds, Private Banking, Brokers, and Households. The category Long-Term includes primarily insurance companies and pension funds, and the category Investment Advisors includes investment advisors and mutual funds. ${ }^{8}$ We use FactSet's classification of investor types to assign institutions to institutional groups. Second, as the group of investment advisors is large, we further split this group of investors

\footnotetext{
${ }^{8}$ FactSet classifies an investment firm as an Investment Advisor when the majority of its investments are not in mutual funds and when it is not a subsidiary of a bank, brokerage firm, or insurance company. If the majority of its investments are in mutual funds, it is instead classified as Mutual Fund. As this classification is economically quite arbitrary, we group investment advisors and mutual funds together.
} 
by assets under management and active share, see Appendix A for further details. Our final groupings are given by Investment Advisors - Large Passive, Investment Advisors - Small

Passive, Investment Advisors - Small Active, Investment Advisors - Large Active, Hedge Funds, Long-Term, Private Banking, Brokers, and Households.

The household sector is constructed so that total holdings of a company add up to the company's market capitalization. In rare instances, the total holdings exceed total market cap, in which case we scale the holdings back proportionally. One reason why this may happen is due to short-selling activity, which are not covered in our data as we only have the long positions (Lewellen 2011).

We construct an annual sample of holdings data that begins in 2006 and ends in 2016. While FactSet has data before 2006, the coverage is incomplete. Firm-level fundamentals are from FactSet for GB, the US, the Euro area (EA), and Japan (JP). We construct annual firm fundamentals from 2006 until 2016. While we do not have detailed holdings data in the Euro area and Japan, we use data on valuation ratios and fundamentals in these regions to show that the fundamentals that we use also explain a large share of the variation in valuation ratios and future profits in these region.

\section{B. Firm granularity}

Table 1 documents firm characteristics along the firm size distribution, as measured by market capitalization. The top two panels are for the US in 2006 and 2016. In 2016, the top $90 \%$ of total market capitalization is accounted for by only 761 firms. The largest 82 firms already account for $50 \%$ of the total market capitalization.

The largest $50 \%$ of firms account for only $38 \%$ of sales, $33 \%$ of investment and employment, yet $63 \%$ of net income. This implies that profits are highly concentrated among the largest firms. By comparing the distribution to 2006, we see that these statistics have been fairly stable over time.

In the bottom two panels, we compute similar statistics for the Euro area, Japan, and GB in 2006 and 2016. The patterns are similar, though less extreme, in other countries. In 2016, the top $50 \%$ of firms is made up by 44, 85, and 22 firms in the Euro area, Japan, and GB, respectively. At the 90th percentile, these numbers change to 274, 682, and 181. 
By comparing the bottom two panels, we find that these statistics have been quite stable over time. To illustrate the concentration at the top, we list the largest 10 firms in each geography in Table 2.

For the remainder of the paper, we focus on the largest $90 \%$ of firms to make sure that we focus on stocks that are sufficiently liquid (see also Asness, Moskowitz, and Pedersen (2013)). We group the bottom 10\% into a small-cap portfolio that becomes an outside asset for the investors. Table 1 shows that the economic impact of these firms is small in terms of employment, investment, and profitability.

\section{Distribution of institutional types}

Figure 2 reports the ownership shares by institutional type, which have been fairly stable during the last decade. Table 3 lists the largest investor by type to provide some perspective on the types of institutions that populate the groups.

The distribution of ownership is concentrated as well (see for instance Azar, Schmalz, and Tecu (2018)), and this concentration has increased over time (Itzhak et al. 2018). To illustrate this in our sample, we list the assets under management in 2016 of the largest 10 investors in the US and GB in Table 4. Part of this concentration is driven by the increased popularity of passive indexing strategies and has resulted in questions regarding the broader impact on market efficiency (Garleanu and Pedersen 2019).

\section{Cross-sectional valuation regressions: Global evidence}

We show that a small set of characteristics explains the majority of the cross-sectional variation in valuation ratios in the US, GB, the Euro area, and in Japan. We use this fact in the specification of our asset demand system.

\section{A. Selection of characteristics}

We consider six characteristics. The first characteristic is log book equity (LNbe), which captures size effects. To forecast future productivity and profitability, we use the sales-tobook equity ratio, the foreign sales share, the dividend-to-book equity ratio, and the Lerner 
index. Our use of the foreign sales share is motivated by models such as Melitz (2003) in which only the most productive firms export to other countries. The Lerner index is a simple measure of markups that is also used in the recent literature on industry concentration and the rise of superstar firms (see for instance Guitierrez and Philippon (2017)). The Lerner index is calculated as operating income after depreciation divided by sales. Lastly, we include a stock's market beta, measured relative to the local market return, as the canonical measure of stock market risk. We cross-sectionally standardize all characteristics by region and year.

\section{B. Explaining valuation ratios using characteristics}

We start with the following panel regression of valuation ratios on the characteristics

$$
m b_{t}(n)=a_{t}+\boldsymbol{\lambda}_{m b}^{\prime} \boldsymbol{x}_{t}(n)+\epsilon_{t}(n)
$$

where $a_{t}$ are time fixed effects. The results are reported for each of the four regions in Table 5 .

First, we find that the coefficient on log book equity is negative, while the productivity and markup variables all enter positively. The negative coefficient on book equity is consistent with equation (8) and points to downward-sloping demand curves for individual stocks, as discussed in the theory in Section I.

Second, the point estimates are quite comparable across regions. The region that deviates somewhat more from the others is Japan. Third, and importantly from our perspective, we can account for a large fraction of the cross-sectional variation in prices using a small set of characteristics. The within-year R-squared ranges from $37 \%$ (in Japan) to $68 \%$ (in GB). In the US, we explain $52 \%$ of the variation in the panel of valuation ratios.

Table 5 shows that the same characteristics also explain a substantial fraction of the cross-sectional variation in future profitability, ${ }^{9}$ often with similar coefficients in terms of sign and magnitude as in the valuation regressions. ${ }^{10}$ We do note that our global sample

\footnotetext{
${ }^{9}$ Following Campbell, Polk, and Vuolteenaho (2009), we use the accounting identity $B_{t}=B_{t-1}+X_{t}-$ $N F_{t}-D_{t}$, where $N F_{t}$ are net issuances, $D_{t}$ cash dividends, $B_{t}$ denotes book equity, and $X_{t}$ the implied earnings. We then define $e_{t}=\ln \left(1+X_{t} / B_{t-1}\right)$ and use as our earnings measure $\sum_{i=1}^{5} \rho^{i} e_{t+i}$ with $\rho=0.95$.

${ }^{10}$ Kacperczyk, Sundaresan, and Wang (2019) show that price informativeness is increasing in the fraction of equity held by foreign investors, in particular in developed economies (see also Bena et al. (2017)).
} 
is quite short, which makes it challenging to accurately estimate expected future earnings. However, our decomposition of the market-to-book-ratio also implies a decomposition of long-horizon expected returns, once combined with a model for expected earnings, via the present-value identities developed in Cohen, Polk, and Vuolteenaho (2003) and Campbell, Polk, and Vuolteenaho (2009). As such, a decomposition of valuations, combined with a model of earnings expectations, yields a decomposition of expected returns. We explore this in more detail in Section VI.

\section{Estimating the asset demand system}

In this section we discuss how we estimate the international asset demand system as summarized by equations (10)-(11) and (12)-(13). We first discuss how we estimate the demand system within a country and then discuss how we can estimate the demand curve across

countries. Readers may choose to skip this section in a first reading of the paper and go directly to Section VI for the empirical results.

\section{A. Estimating the within-country demand system}

The estimating equation Our goal in this section is to estimate the demand curve of investor $i$ in a given country, which can be written as

$$
\frac{w_{i, t}(n)}{w_{i, t}(0)}=\exp \left\{b_{0, i, t}+\beta_{0, i} m b_{t}(n)+\boldsymbol{\beta}_{1, i}^{\prime} \boldsymbol{x}_{t}^{\star}(n)\right\} \epsilon_{i, t}(n)
$$

where we omit country subscripts to simplify the notation as we focus on the within-country demand system. We standardize all the characteristics cross-sectionally, denoted by $\boldsymbol{x}_{t}^{\star}(n)$, and order them such that the first characteristic is log book equity, be $e_{t}(n)$.

We assume throughout this section that characteristics are exogenous to latent demand,

$$
\mathbb{E}_{t}\left[\epsilon_{i, t}(n) \mid \boldsymbol{x}_{t}^{\star}(n)\right]=1
$$

where the expectation is taken across stocks in a given period as we include time fixed effects.

There are two challenges in estimating the demand curve. First, prices are endogenous 
to latent demand. We therefore first discuss the details of our instrument, $z_{i, t}(n)$. Second, as some investors hold concentrated portfolios, we may not be able to estimate all coefficients precisely. We propose a shrinkage estimator of the coefficients, which avoids pooling across investors.

Construction of the instrument We cannot simply estimate investors' demand curves using ordinary least squares, as latent demand is likely correlated with prices. This correlation could be a result of investors not being atomistic or correlated demand shocks across investors. To construct an instrument, we follow Koijen and Yogo (2019) and use exogenous variation in investors' investment mandates to generate exogenous variation in demand.

The key economic assumption is that the set of stocks that an investor holds over time is exogenous. Investors may drop certain stocks in a particular year as a result of variation in latent demand, that is, $\epsilon_{i, t}(n)$ and $\mathcal{N}_{i, t}$ are correlated, but the boundaries of the investment universe, $\mathcal{N}_{i}=\cup_{t=1}^{T} \mathcal{N}_{i, t}$, are assumed to be exogenous. The boundaries of an investor's investment universe in case of institutional investors is typically determined by investment mandates.

Within the universe of mandates, the actual portfolio holdings are endogenous. As instruments, we compute the counterfactual prices as if investors hold a $1 /\left(1+\left|\mathcal{N}_{j}\right|\right)$ portfolio, excluding the investor's own assets and the assets of the household sector

$$
z_{i, t}(n)=\log \left(\sum_{j \neq i, H H} A_{j, t} \frac{1_{j}(n)}{1+\left|\mathcal{N}_{j}\right|}\right)
$$

A ridge-IV estimator of the demand curve We now discuss how we modify the standard GMM moment conditions to impose the shrinkage penalty and how we choose the shrinkage target. This allows us to estimate separate demand curves for each investor, instead of pooling across investors.

We start from the moment conditions based on (20),

$$
\mathbb{E}_{t}\left[\left(\frac{w_{i, t}(n)}{w_{i, t}(0)} \exp \left\{-\boldsymbol{\beta}_{i}^{\prime} \boldsymbol{X}_{t}(n)\right\}-1\right) \boldsymbol{Z}_{t}(n)\right]=0
$$


where $\boldsymbol{X}_{t}(n)=\left(m b_{t}(n), \boldsymbol{x}_{t}^{\star \prime}(n), \boldsymbol{d}_{t}^{\prime}\right)^{\prime}, \boldsymbol{\beta}_{i}=\left(\beta_{0, i}, \boldsymbol{\beta}_{1, i}^{\prime}, \boldsymbol{\beta}_{2, i}^{\prime}\right)^{\prime}, \boldsymbol{Z}_{t}(n)=\left(\widehat{z}_{t}, \boldsymbol{x}_{t}^{\star \prime}(n), \boldsymbol{d}_{t}^{\prime}\right)^{\prime}$, and $\boldsymbol{d}_{t}$ a vector of time fixed effects. In forming the moment conditions, we use the projection of $m b_{t}(n)$ on $\left(z_{i, t}(n), \boldsymbol{x}_{t}^{\star}(n), \boldsymbol{d}_{t}\right)$, denoted by $\widehat{z}_{t}$, as in case of linear two-stage least squares.

We implement the shrinkage estimator by adding a ridge penalty (Hoerl and Kennard 1970) to the moment conditions:

$$
\mathbb{E}_{t}\left[\left(\frac{w_{i, t}(n)}{w_{i, t}(0)} \exp \left\{-\boldsymbol{\beta}_{i}^{\prime} \boldsymbol{X}_{t}(n)\right\}-1\right) Z_{t}(n)\right]-D\left(\boldsymbol{\Lambda}_{i}\right)\left(\boldsymbol{\beta}_{i}-\boldsymbol{\beta}^{T}\right)=0
$$

The term $D\left(\boldsymbol{\Lambda}_{i}\right)\left(\boldsymbol{\beta}_{i}-\boldsymbol{\beta}^{T}\right)$ is the ridge penalty, where $D(\boldsymbol{v})$ denotes a diagonal matrix with the elements of the vector $\boldsymbol{v}$ on the diagonal.

The shrinkage target, $\boldsymbol{\beta}^{T}$, equals $\boldsymbol{\beta}^{T}=\left(\beta_{0, i}^{T}, \boldsymbol{\beta}_{1, i \times K}^{T}, \mathbf{0}_{1 \times T}\right)^{\prime}$. For investors with more than 1,500 observations, across stocks and years, we can estimate $\left(\beta_{0, i}, \boldsymbol{\beta}_{1, i}^{\prime}\right)^{\prime}$ without any shrinkage as we can estimate their demand curves accurately. We use the (equal-weighted) average of these estimates across investors with greater than 1,500 observations as the shrinkage target.

We set the shrinkage penalty to $\lambda N_{i}^{-\xi}$, with $\xi>0$. This implies that the penalty becomes less important as investors hold more stocks. $\xi$ controls the speed at which the penalty vanishes asymptotically. If the implied estimates result in an estimate of $\beta_{i, 0}$ that exceeds 1 , then we increase the first element of $\boldsymbol{\Lambda}_{i}$ to $\infty$ to impose $\beta_{0, i}=1$. Even though the moment conditions in (22) are non-linear, we develop a simple numerical algorithm to solve them efficiently as we discuss in Appendix C.

To complete the estimation procedure, we need to determine $(\lambda, \xi)$. As is common practice in the machine learning literature, we choose both parameters using cross-validation. In particular, we split the holdings randomly in half for each investor by year. We then estimate the model on one sample for each investor and compute the mean-squared error on the left out sample. The mean-squared error is minimized for $(\lambda, \xi)=(15,0.8)$. 


\section{B. Estimating the cross-country demand curves}

To complete the model's estimation, we estimate $\psi_{0, i}$ and $\psi_{1, i}$ in (12)-(13) that determine the cross-country demand curves. The model implies

$$
\begin{aligned}
\ln \left(\frac{w_{i, t}(U S)}{w_{i, t}(G B)}\right) & =\psi_{0, i}+\psi_{1, i} \ln \left(\frac{\zeta_{i, t}(U S)}{\zeta_{i, t}(G B)}\right)+\epsilon_{i, t}^{\psi} \\
& =\psi_{0, i}-\psi_{1, i} \ln \left(\frac{w_{i, t}(0 \mid U S)}{w_{i, t}(0 \mid G B)}\right)+\epsilon_{i, t}^{\psi}
\end{aligned}
$$

where we use $\zeta_{i, t}(c)=\frac{1}{w_{i, t}(0 \mid c)}$. Equation (23) highlights that $\psi_{0, i}$ controls the average allocation to GB relative to the US. $-\psi_{i, 1}$ is the elasticity of the total GB-US share with respect to the GB-US share in the respective outside assets. Intuitively, $\psi_{1 i}$ measures how much an investor would shift assets from GB to the US when, within GB, the investor shifts from inside assets to the outside asset.

We estimate (23) using a pooled regression by investor type with investor fixed effects, which allows the share in the outside asset to be different across investors. The investor fixed effects provide an estimate of $\psi_{i, 0}$ and that we use within-investor variation in the GB-US share over time to identify $\psi_{1}$.

\section{Empirical results}

We report the estimation results in Section A. In Section B, we define the counterfactual to determine how much different investors matter for asset prices and report the results in Section C. In Section D, we explore the link between investors' size and repricing in more detail. Lastly, we show how different investors impact the link between characteristics and either valuations or expected returns in Section E.

\section{A. Estimation results}

Table 6 summarizes the estimation results for the US (top panel) and GB (middle panel). In the bottom panel, we report the estimates of the cross-country allocation model, that is, $\psi_{1, i}$. The columns correspond to different institutional types and we report the AUM-weighted average of the coefficients in the table. In Figure 3, we summarize the results graphically for 
the US.

In the top and middle panel, the coefficient on the log market-to-book ratio, $\beta_{0, i, c}$, captures the demand elasticity with respect to price. Lower values correspond to demand curves that are more sensitive to prices. We find that hedge funds are the most elastic institutional investors, while long-term investors (pension funds and insurance companies) and large, passive investment advisors are the least elastic investors in both countries. Moreover, active investment advisors are more price elastic, conditional on size, compared to passive investment advisors.

The remaining coefficients reflect the response of demand to characteristics. The estimates imply that investors disagree in particular about the valuation of dividend-to-book equity, log book equity, and foreign sales in both countries. For large, passive investment advisors, all coefficients are close to zero and the coefficient on log book equity is close to one, consistent with these investors holding a market portfolio.

In the bottom panel of Table 6, we report the estimates of $\psi_{1, i}$ in equation (12). Recall that $\psi_{1}$ equal to one corresponds to the same substitution patterns across and within countries, while $\psi_{1}$ equal to zero implies that the cross-country shares are insensitive to relative prices and characteristics. The estimates are relatively close to zero, suggesting limited substitutability across countries.

\section{B. Measuring the importance of investors for asset prices}

The impact on asset prices of switching one particular group of institutional investors to market weights is determined by: (i) their relative size, (ii) how different their demand curve is from the other investors, and (iii) how price sensitive the other investors are, that is, how much do prices need to move for other investors to absorb the demand, as so far as it deviated from the market portfolio.

To measure the relative contribution of different investors to asset prices, we compute prices under the assumption that one group of institutional investors switches to holding the market portfolio. As explained in Section I, this implicitly implies that we assign the size-weighted demand curve of all other investors to this group.

In computing the counterfactual, we switch, for instance, hedge funds both in the US 
and GB to the market portfolio, based on the investor's choice set, and solve for asset prices. Specifically, to compute the counterfactual using the estimated demand system, we set $\beta_{0, i}=1, \beta_{1, i}=e_{1} \sigma_{b}$, and $\epsilon_{i}(n)=0$, for all $n$. We adjust the constant to ensure that the fraction invested in the outside asset, given initial prices, is unaffected. ${ }^{11}$ We then solve for market clearing prices, $M E_{t}^{C F}(n, c)$ using the algorithm in Koijen and Yogo (2019) and our market clearing equation (equation 17). In doing so, we allow investors also to rebalance across countries according to equation (12) and (13). With these counterfactual asset prices we can study how much asset prices change on average, but can also re-run the valuation regressions as in Section IV to understand how much different investors matter for incorporating information about fundamentals into prices.

\section{How much do different investors matter for asset prices?}

To measure the average change in valuations, we compute the following statistic

$$
\theta=\frac{1}{T} \sum_{t}\left(\frac{\sum_{n=1}^{N}\left|M E_{t}^{C F}(n)-M E_{t}(n)\right|}{\sum_{n=1}^{N} M E_{t}(n)}\right)
$$

which measures the total repricing if we change a group's demand to holding the market portfolio. We report the results in Table 7, in which the top panel reports the results for asset prices in the US and the bottom panel for asset prices in GB. The first column shows the share of AUM of that investor type, the second column our measure of total repricing, the third column shows total repricing scaled by an investor type's total AUM, and the fourth column shows repricing assuming that the price elasticity of demand is equal to one.

In both countries, there is a strong relation between the size of the sector and the impact on prices. While part of this is mechanical, the impact is far from proportional. To see this, we scale total repricing by the share of each investor types AUM. The ratio is 0.37 for large, passive investment advisors, 0.39 for long-term investors, 0.75 for broker dealers, ${ }^{12}$ and

${ }^{11}$ To be precise, we set the constant to

$$
b_{0, i, c, t}=\ln \left(\frac{w_{i, t}^{-1}(0, c)-1}{\sum_{m \in \mathcal{N}_{i, c}} \exp \left(\ln M E_{t}(m)\right)}\right),
$$

where $w_{i, t}(0, c)$ and $M E$ are measured before the counterfactual.

${ }^{12}$ We only measure the direct impact of changing the holdings of the broker-dealer sector. It may well 
1.37 for hedge funds. This points to the relative importance of hedge funds in determining asset prices, while large, passive investment advisors and long-term investors already follow strategies that are relatively close to holding the market portfolio.

For comparison, we also present repricing under the assumption that the elasticity of demand is equal to one - a common magnitude found in the literature (Shleifer 1986; Chang, Hong, and Liskovich 2015). To calculate this repricing we multiply each investors AUM share by their active share (times two). This hypothetical repricing has a similar magnitude to ours, although there are differences. For example, our total repricing for large, passive investors is higher $(8.5 \%)$ than the repricing with unit elasticity of demand $(7.3 \%)$. The differences between our total repricing and the unit elasticity of demand repricing points to heterogeneity in slopes of demand curves across investors who specialize in different sets of stocks.

Across countries, we find that switching investors to the market portfolio has a larger impact in the US compared to GB. The effects in GB are smaller for two reasons: (i) the household sector is larger and (ii) our estimates imply that the household sector in GB is more price elastic than the household sector in the US. Any shock to the demand curves of institutions therefore has a smaller impact on asset prices.

In Table 8, we summarize the most influential investors by type. This calculation reveals some striking differences. For instance, the repricing measure for The Vanguard Group, a large, passive investor, is $2.98 \%$, although they manage almost $\$ 1.6$ trillion in assets in 2016. Capital Research \& Management, a large, active investment advisor, has almost the same repricing impact of $2.46 \%$, but managing a sixth of Vanguard's assets at $\$ 250$ billion. Similarly, AQR Capital Management, the hedge fund with the highest repricing measure, has a repricing measure of $0.59 \%$ while investing $\$ 62$ billion in assets. Per dollar of AUM, Capital Research and AQR have approximately the same impact on prices, and substantially more than Vanguard.

be the case, however, that by restricting leverage, broker-dealers have an outsized effect on other investors, which has a larger overall impact on prices. 


\section{Investor size and repricing}

In Figure 4, we explore the link between investor size and repricing in more detail. Investors' active share is negatively correlated with size, as is well known. When splitting institutions into five groups of equal size by AUM, the repricing measure is negatively correlated with size, both in absolute terms and when scaled by AUM.

These effects are larger compared to the differences assuming that the elasticity of demand equals one, which also points to differences in the slopes of demand curves. Heuristically, if the slopes of demand curves would be the same and equal to one, our repricing measure would simplify to repricing $=$ active share $\times 2 \times$ AUM share.

Indeed, we find that small, active investment advisors and hedge funds are the most price elastic institutional investors. This implies that when those institutions switch to holding a market indexing strategy, prices need to move more to change the portfolios of, for instance, large, passive investors.

\section{E. Linking characteristics to valuation ratios and long-horizon expected returns}

Beyond the overall importance of different investor types for the cross-section of valuation ratios, we can also quantify how important investor types are to link firm characteristics to valuation ratios. This is useful as large literatures in accounting and finance discover characteristics that are linked to valuation ratios or expected returns, and researchers oftentimes attempt to explain such price patterns by linking it to the demand curves of different investors such as the sentiment of retail investors, smart money (e.g., hedge funds), or longterm investors such as pension funds and insurance companies. By providing a framework to quantitatively assess the importance of various investor types, we can make the connection between the models or narratives and the data precise.

To show how important different investors are to link a particular characteristic to valuation ratios, we re-run the valuation regressions by regressing the counterfactual log marketto-book ratios on characteristics in a panel with time fixed effects, as in (18). We then compute the change in loadings on characteristics.

The results are presented in Table 9 for the US (top panel) and GB (bottom panel). 
The columns correspond to different counterfactuals. To simplify the interpretation of the results, we scale the change in coefficients by the values in Table 5 and multiply by 100 . For instance, -10.9 for small, active investment advisors in the case of fraction of foreign sales means that the coefficient in valuations regressions on this characteristic would be $10.9 \%$ smaller if small, active investment advisors switch to a market-weighted portfolio.

Small, active investment advisors are most important for the pricing of foreign sales $(-10.9 \%)$, cash flows as measured by sales-to-book (19\%), payout policy as measured by dividend-to-book (63.7\%), and firm size (48.0\%). For the Lerner index, large, passive investment advisors are most important (23.0\%), while hedge funds are most influential in pricing market beta (-33.7\%). Hedge funds are generally quite important, as their impact on the coefficient of the Lerner index is $20.2 \%, 22.8 \%$ for dividend-to-book, $10.9 \%$ for firm size, and $8.4 \%$ for the foreign sales share. As discussed before, the influence of hedge funds is remarkable given their relatively small size.

For GB, small, active investment advisors are most important in pricing size (12.1\%) and payout policy (5.1\%), while large, active investment advisors are most important for the Lerner index (19.3\%) and market beta (35.9\%). Large, passive investors are most influential in pricing foreign sales $(-8.0 \%)$.

\section{F. The impact of investors on long-horizon expected returns}

To map changes in valuations, and their connection to characteristics, to expected returns, we use the valuation model of Cohen, Polk, and Vuolteenaho (2003) and Campbell, Polk, and Vuolteenaho (2009). We write the $\log$ market-to-book ratio of firm $n, m b_{t}(n)$, as

$$
m b_{t}(n)=\sum_{s=1}^{\infty} \rho^{s-1} \mathbb{E}_{t}\left[e_{t+s}(n)\right]-\sum_{s=1}^{\infty} \rho^{s-1} \mathbb{E}_{t}\left[r_{t+s}(n)\right]
$$

where

$$
\begin{aligned}
& e_{t}(n)=\ln \left(1+\frac{\Delta B E_{t}(n)+D_{t}(n)}{B E_{t-1}(n)}\right) \\
& r_{t}(n)=\ln \left(1+\frac{\Delta M E_{t}(n)+D_{t}(n)}{M E_{t-1}(n)}\right)
\end{aligned}
$$


and $B E_{t}(n)$ a firm's book equity, $M E_{t}(n)$ its market equity, and $D_{t}(n)$ its dividend. ${ }^{13}$

To convert these estimates to expected returns, we make the simplifying assumption that expected growth rates, $g_{t}$, and expected returns, $\mu_{t}$, are random walks, which is not unreasonable given the extreme persistence in these series. The expression for the marketto-book ratio now simplifies to

$$
m b_{t}(n)=C+\frac{g_{t}}{1-\rho}-\frac{\mu_{t}}{1-\rho} .
$$

If the link between characteristics and expected growth rates does not change in the counterfactuals, then the change in valuation ratios links one-to-one to changes in expected returns, with a scaling coefficient of $(1-\rho)^{-1}$. Using a typical value of $\rho=0.95$, we obtain that the scaling factor is around 20 in mapping changes in valuations to changes in expected returns. The impact on expected returns would be larger in case expected returns are persistent but not a random walk. ${ }^{14}$

Hence, using the estimate of 10.47 as before, the relation between dividend-to-book equity and expected returns would change by $52 \mathrm{bp}$ per year for a one standard deviation change in dividend to book equity. If expected returns are less (more) persistent, for instance because characteristics are less (more) persistent, then these effects would be larger (smaller).

\section{Conclusion}

It is common practice to decompose levels and variation in prices into expected returns and expected fundamentals. However, it is unclear what information investors use for prices to be informative and how important different investors are for incorporating information into prices.

We show that a small set of characteristics explains the majority of the variation in a panel of firm-level valuation ratios across countries. The same characteristics also predict future profitability with comparable coefficients. To measure how investors' demands respond to

\footnotetext{
${ }^{13}$ As we use characteristics throughout this paper, Appendix D shows how one could compute variance decompositions in characteristics space.

${ }^{14}$ Alternatively, the scaling coefficient equals $\left(1-\rho \varphi_{\mu}\right)^{-1}$ if expected returns follow an $\mathrm{AR}(1)$ with autoregressive parameter $\varphi_{\mu}$. Using the estimates in Binsbergen and Koijen (2010), the scaling coefficient is $(1-0.932 \times 0.969)^{-1} \simeq 10$.
} 
the characteristics, we estimate a demand system in Great Britain and in the United States. The demand system allows us to quantify the importance of different institutional types (e.g., mutual funds, broker dealers, ... ) for price formation by computing counterfactual prices if a particular type were to follow a market-indexing strategy. By combining these estimates with our forecasts of future profitability, we measure the contribution of each institutional type to cross-sectional variation in long-term expected returns.

Our framework can be used whenever one is interested in understanding why certain characteristics affect the cross-section of valuation ratios or long-term expected returns. For instance, our approach may be useful in understanding which investors matter most in connecting asset prices to corporate governance, or ESG factors model broadly (Baker et al. 2018), how risk is priced (Pflueger, Siriwardane, and Sunderam 2018), et cetera.

By focusing on groups of intermediaries, which may differ in terms of regulations, funding structure, and investment horizon, our approach may inform the growing theoretical literature on intermediary asset pricing to develop micro-foundations for the demand curves that we estimate for different intermediaries. 


\section{References}

Asness, Clifford S., Tobias J. Moskowitz, and Lasse Heje Pedersen. 2013. "Value and Momentum Everywhere." Journal of Finance 68 (3):929-986.

Autor, David, David Dorn, Lawrence F Katz, Christina Patterson, and John Van Reenen. 2020. "The Fall of the Labor Share and the Rise of Superstar Firms*." The Quarterly Journal of Economics 135 (2):645-709. URL https://doi.org/10.1093/qje/qjaa004.

Azar, Jose, Martin Schmalz, and Isabel Tecu. 2018. "Anticompetitive Effects of Common Ownership." Journal of Finance 73 (4):1513-1565.

Baker, Malcolm, Daniel Bergstresser, George Serafeim, and Jeffrey Wurgler. 2018. "Financing the Response to Climate Change: The Pricing and Ownership of U.S. Green Bonds." Working paper, Harvard Business School .

Barberis, Nicholas, Andrei Shleifer, and Robert Vishny. 1998. "A Model of Investor Sentiment." Journal of Financial Economics 49:307-343.

Barbon, Andrea and Virginia Gianinazzi. 2019. "Quantitative Easing and Equity Prices: Evidence from the ETF Program of the Bank of Japan." The Review of Asset Pricing Studies 9 (2):210-255. URL https://doi.org/10.1093/rapstu/raz008.

Bebchuk, Lucian, Alma Cohen, and Allen Ferrell. 2008. "What Matters in Corporate Governance?" The Review of Financial Studies 22 (2):783-827. URL https://doi.org/10. 1093/rfs/hhn099.

Bena, Jan, Miguel A. Ferreira, Pedro Matos, and Pedro Pires. 2017. "Are Foreign Investors Locusts? The Long-Term Effects of Foreign Institutional Ownership." Journal of Financial Economics 126 (1):122-146.

Binsbergen, Jules H. van and Ralph S.J. Koijen. 2010. "Predictive Regressions: A PresentValue Approach." Journal of Finance 65:1439-1471.

Brunnermeier, Markus K. and Lasse Heje Pedersen. 2009. "Market Liquidity and Funding Liquidity." Review of Financial Studies 22 (6):2201-2238. 
Campbell, John Y., Christopher Polk, and Tuomo Vuolteenaho. 2009. "Growth or Glamour? Fundamentals and Systematic Risk in Stock Returns." Review of Financial Studies $23(1): 305-344$.

Campbell, John Y. and Robert J. Shiller. 1988. "The Dividend-Price Ratio and Expectations of Future Dividends and Discount Factors." Review of Financial Studies 1 (3):195-228.

Chang, Yen-Cheng, Harrison Hong, and Inessa Liskovich. 2015. "Regression discontinuity and the price effects of stock market indexing." The Review of Financial Studies $28(1): 212-246$.

Cohen, Randolph B., Christopher Polk, and Tuomo Vuolteenaho. 2003. "The Value Spread." Journal of Finance 58 (2):609-641.

Daniel, Kent and Sheridan Titman. 2006. "Market Reactions to Tangible and Intangible Information." Journal of Finance 61 (4):1605-1643.

Fama, Eugene F. and Kenneth R. French. 1995. "Size and Book-to-Market Factors in Earnings and Returns." Journal of Finance 50 (1):131-155.

Fillat, Jos L. and Stefania Garetto. 2015. "Risk, Returns, and Multinational Production *." The Quarterly Journal of Economics 130 (4):2027-2073. URL https://doi.org/10. 1093/qje/qjv031.

Garleanu, Nicolae and Lasse Pedersen. 2019. "Active and Passive Investing." Working paper, University of California, Berkeley - Haas School of Business .

Giroud, Xavier and Holger M. Mueller. 2011. "Corporate Governance, Product Market Competition, and Equity Prices." The Journal of Finance 66 (2):563-600. URL https: //onlinelibrary.wiley.com/doi/abs/10.1111/j.1540-6261.2010.01642.x.

Gompers, Paul, Joy Ishii, and Andrew Metrick. 2003. "Corporate Governance and Equity Prices*." The Quarterly Journal of Economics 118 (1):107-156. URL https://doi.org/ $10.1162 / 00335530360535162$. 
Guitierrez, German and Thomas Philippon. 2017. "Declining Competition and Investment in the U.S." Working paper, NYU Stern.

Hoerl, Arthur E. and Robert W. Kennard. 1970. "Ridge Regression: Biased Estimation for Nonorthogonal Problems." Technometrics 12 (1):55-67.

Hong, Harrison and Marcin Kacperczyk. 2009. "The price of sin: The effects of social norms on markets." Journal of Financial Economics 93 (1):15 - 36. URL http://www . sciencedirect.com/science/article/pii/S0304405X09000634.

Itzhak, Ben-David, Francesco A. Franzoni, Rabih Moussawi, and John Sedunov. 2018. "The Granular Nature of Large Institutional Investors." Working paper, Ohio State University.

Kacperczyk, Marcin T., Savitar Sundaresan, and Tianyu Wang. 2019. "Do Foreign Institutional Investors Improve Market Efficiency?" Working paper, Imperial College London.

Koijen, Ralph S.J. and Motohiro Yogo. 2019. "A Demand System Approach to Asset Pricing." Journal of Political Economy, Forthcoming.

La Porta, Rafael. 1996. "Expectations and the Cross-Section of Stock Returns." The Journal of Finance 51 (5):1715-1742. URL https://onlinelibrary.wiley.com/doi/abs/10. $1111 / j \cdot 1540-6261.1996 . t b 05223 . x$.

La Porta, Rafael, Florencio Lopez-De-Silanes, Andrei Shleifer, and Robert Vishny. 2002. "Investor Protection and Corporate Valuation." The Journal of Finance 57 (3):11471170. URL https://onlinelibrary.wiley.com/doi/abs/10.1111/1540-6261.00457.

Lewellen, Jonathan. 2011. "Institutional Investors and the Limits of Arbitrage." Journal of Financial Economics 102 (1):62-80.

Lucas, Robert E., Jr. 1978. "Asset Prices in an Exchange Economy." Econometrica 46 (6):1429-1445.

Makarov, Dmitry and Astrid Schornick. 2010. "A Note on Wealth Effect under CARA Utility." Finance Research Letters 7 (3):170-177. 
Melitz, Marc. 2003. "The Impact of Trade on Intra-Industry Reallocations and Aggregate Industry Productivity." Econometrica 71 (6):1695-1725.

Merton, Robert C. 1987. "A Simple Model of Capital Market Equilibrium with Incomplete Information." Journal of Finance 42 (3):483-510.

Pflueger, Carolin, Emil Siriwardane, and Adits Sunderam. 2018. "A Measure of Risk Appetite for the Macroeconomy." Working paper, UBC .

Shleifer, Andrei. 1986. "Do demand curves for stocks slope down?" The Journal of Finance $41(3): 579-590$.

Vuolteenaho, Tuomo. 2002. "What Drives Firm-Level Stock Returns?" Journal of Finance $57(1): 233-264$.

Yermack, David. 1996. "Higher market valuation of companies with a small board of directors." Journal of Financial Economics 40 (2):185 - 211. URL http://www. sciencedirect.com/science/article/pii/0304405X95008445. 
Table 1

Firm Size Distribution by Region

\begin{tabular}{|c|c|c|c|c|c|c|}
\hline Region & Mkt Pct & Number of Firms & Sales Pct & NI. Pct & Inv. Pct & Emp. Pct \\
\hline \multicolumn{7}{|c|}{ United States (2016) } \\
\hline & 10 & 5 & 6 & 15 & 8 & 2 \\
\hline & 20 & 14 & 13 & 27 & 15 & 7 \\
\hline & 30 & 26 & 22 & 40 & 22 & 18 \\
\hline & 40 & 47 & 29 & 53 & 25 & 26 \\
\hline & 50 & 82 & 38 & 63 & 32 & 33 \\
\hline & 60 & 138 & 50 & 75 & 46 & 42 \\
\hline & 70 & 231 & 64 & 84 & 60 & 53 \\
\hline & 80 & 396 & 73 & 91 & 72 & 62 \\
\hline & 90 & 761 & 85 & 99 & 84 & 77 \\
\hline & 100 & 3622 & 100 & 100 & 100 & 100 \\
\hline \multicolumn{7}{|c|}{ United States (2006) } \\
\hline & 10 & 6 & 8 & 15 & 7 & 3 \\
\hline & 20 & 14 & 16 & 25 & 14 & 12 \\
\hline & 30 & 27 & 24 & 36 & 24 & 17 \\
\hline & 40 & 49 & 31 & 46 & 29 & 22 \\
\hline & 50 & 84 & 41 & 58 & 37 & 31 \\
\hline & 60 & 146 & 52 & 67 & 46 & 40 \\
\hline & 70 & 242 & 64 & 77 & 59 & 52 \\
\hline & 80 & 423 & 75 & 86 & 69 & 63 \\
\hline & 90 & 872 & 87 & 95 & 83 & 78 \\
\hline & 100 & 4673 & 100 & 100 & 100 & 100 \\
\hline \multicolumn{7}{|c|}{2016} \\
\hline Great Britain & 50 & 22 & 40 & 40 & 47 & 28 \\
\hline Great Britain & 90 & 181 & 87 & 91 & 86 & 79 \\
\hline Euro Area & 50 & 44 & 40 & 53 & 48 & 33 \\
\hline Euro Area & 90 & 274 & 87 & 90 & 89 & 81 \\
\hline Japan & 50 & 85 & 38 & 54 & 50 & 34 \\
\hline Japan & 90 & 682 & 83 & 90 & 90 & 80 \\
\hline \multicolumn{7}{|c|}{2006} \\
\hline Great Britain & 50 & 17 & 46 & 46 & 48 & 28 \\
\hline Great Britain & 90 & 155 & 89 & 92 & 89 & 81 \\
\hline Euro Area & 50 & 51 & 48 & 59 & 52 & 35 \\
\hline Euro Area & 90 & 304 & 87 & 92 & 89 & 80 \\
\hline Japan & 50 & 70 & 38 & 54 & 48 & 35 \\
\hline Japan & 90 & 657 & 81 & 91 & 84 & 80 \\
\hline
\end{tabular}

Each row represents the number of companies as well as the fraction of sales, net income, investment, and employment represented by the top deciles of market cap. Firm-level fundamentals are annual from FactSet from 2006 to 2016. 
Table 2

Market Capitalization of Largest Companies by Region in 2016

\begin{tabular}{|c|c|c|c|}
\hline \multicolumn{2}{|l|}{ United States } & \multicolumn{2}{|l|}{ Great Britain } \\
\hline Apple Inc & 609 & HSBC Holdings Plc & 161 \\
\hline Alphabet Inc & 548 & BP Plc & 122 \\
\hline Microsoft Corp & 480 & British American Tobacco plc & 106 \\
\hline Berkshire Hathaway Inc & 402 & GlaxoSmithKline Plc & 94 \\
\hline Exxon Mobil Corp & 374 & AstraZeneca Plc & 69 \\
\hline Amazoncom Inc & 358 & Vodafone Group Plc & 66 \\
\hline Facebook Inc & 333 & Diageo Plc & 66 \\
\hline Johnson Johnson & 312 & Reckitt Benckiser Group Plc & 60 \\
\hline JPMorgan Chase Co & 307 & Lloyds Banking Group Plc & 55 \\
\hline Wells Fargo Co & 276 & Prudential Plc & 52 \\
\hline \multicolumn{2}{|l|}{ Euro Area } & \multicolumn{2}{|l|}{ Japan } \\
\hline Royal Dutch Shell Plc & 237 & Toyota Motor Corp & 176 \\
\hline AnheuserBusch InBev SA/NV & 205 & Nippon Telegraph Telephone Corp & 86 \\
\hline Total SA & 124 & NTT DoCoMo Inc & 85 \\
\hline Unilever NV & 117 & Mitsubishi UFJ Financial Group Inc & 83 \\
\hline Industria de Diseo Textil SA & 107 & SoftBank Group Corp & 73 \\
\hline Siemens AG & 105 & KDDI Corp & 62 \\
\hline SAP SE & 105 & Japan Tobacco Inc & 59 \\
\hline L'Oreal SA & 102 & Honda Motor Co Ltd & 53 \\
\hline Sanofi & 102 & Sumitomo Mitsui Financial Group Inc & 52 \\
\hline Medtronic Plc & 98 & Mizuho Financial Group Inc & 46 \\
\hline
\end{tabular}

Top 10 companies by market cap within each region in 2016. Market cap is in billions of USD. Price data is from FactSet. 
Table 3

Largest Investors by Type

\begin{tabular}{llr}
\hline Type & Investor & AUM \\
\hline Households & & 6588 \\
Inv. Large Passive & The Vanguard Group, Inc. & 1598 \\
Inv. Large Active & T. Rowe Price Associates, Inc. & 423 \\
Long-Term & Norges Bank Investment Management & 199 \\
Private Banking & Goldman Sachs \& Co. LLC (Private Banking) & 99 \\
Inv. Small Passive & Managed Account Advisors LLC & 94 \\
Inv. Small Active & PRIMECAP Management Co. & 84 \\
Hedge Funds & AQR Capital Management LLC & 62 \\
Brokers & Credit Suisse Securities (USA) LLC (Broker) & 60 \\
\hline
\end{tabular}

Largest investors in the United States by assets under management for each type in 2016 . Equity holdings data are from FactSet. 
Table 4

Largest Investors

\begin{tabular}{llr}
\hline Investor & Type & AUM \\
\hline \multicolumn{1}{c}{ United States (2016) } & & \\
\hline The Vanguard Group, Inc. & Inv. Large Passive r & 1598 \\
BlackRock Fund Advisors & Inv. Large Passive & 1069 \\
SSgA Funds Management, Inc. & Inv. Large Passive & 954 \\
Fidelity Management \& Research Co. & Inv. Large Passive & 554 \\
T. Rowe Price Associates, Inc. & Inv. Large Active & 423 \\
Capital Research \& Management Co. (World Investors) & Inv. Large Passive & 328 \\
Wellington Management Co. LLP & Inv. Large Active & 324 \\
Northern Trust Investments, Inc. & Inv. Large Passive & 276 \\
Capital Research \& Management Co. (Global Investors) & Inv. Large Active & 250 \\
Norges Bank Investment Management & Long-Term & 199 \\
Total & & $\mathbf{5 9 7 4}$ \\
\hline \multicolumn{1}{c}{ Great Britain (2016) } & & \\
\hline The Vanguard Group, Inc. & Inv. Large Passive & 61 \\
Legal \& General Investment Management Ltd. & Inv. Small Passive & 47 \\
Norges Bank Investment Management & Long-Term & 45 \\
BlackRock Investment Management (UK) Ltd. & Inv. Large Passive & 43 \\
BlackRock Advisors (UK) Ltd. & Inv. Small Passive & 28 \\
Invesco Asset Management Ltd. & Inv. Large Active & 28 \\
Capital Research \& Management Co. (World Investors) & Inv. Large Passive & 28 \\
Capital Research \& Management Co. (Global Investors) & Inv. Large Active & 27 \\
SSgA Funds Management, Inc. & Inv. Large Passive & 27 \\
BlackRock Fund Advisors & Inv. Large Passive & 27 \\
Total & & $\mathbf{3 5 9}$ \\
\hline
\end{tabular}

Top 10 institutional investors by assets under management in the United States and Great Britain in 2016. Equity holdings data are from FactSet. 
Table 5

Valuation and Earnings Regressions (4 Regions)

\begin{tabular}{|c|c|c|c|c|c|c|c|c|}
\hline & \multicolumn{2}{|c|}{ United States } & \multicolumn{2}{|c|}{ Great Britain } & \multicolumn{2}{|c|}{ Euro Area } & \multicolumn{2}{|c|}{ Japan } \\
\hline & $m b$ & $e^{5}$ & $m b$ & $e^{5}$ & $m b$ & $e^{5}$ & $m b$ & $e^{5}$ \\
\hline \multirow[t]{2}{*}{ Foreign Sales } & 0.16 & 0.07 & 0.12 & 0.08 & 0.12 & 0.02 & 0.10 & 0.00 \\
\hline & $(21.61)$ & $(5.52)$ & $(5.85)$ & $(1.83)$ & $(7.75)$ & $(2.69)$ & $(7.73)$ & $(0.34)$ \\
\hline \multirow[t]{2}{*}{ Lerner } & 0.06 & 0.13 & 0.06 & 0.15 & 0.11 & 0.08 & 0.13 & 0.10 \\
\hline & $(5.27)$ & $(9.74)$ & $(2.75)$ & $(3.43)$ & $(6.22)$ & $(8.57)$ & $(11.92)$ & $(6.81)$ \\
\hline \multirow[t]{2}{*}{ Sales to Book } & 0.19 & 0.19 & 0.21 & 0.16 & 0.14 & 0.06 & 0.15 & 0.09 \\
\hline & $(30.52)$ & $(18.48)$ & $(5.82)$ & $(2.02)$ & $(16.67)$ & $(4.29)$ & $(17.54)$ & $(20.20)$ \\
\hline \multirow[t]{2}{*}{ Dividend to Book } & 0.16 & 0.10 & 0.32 & 0.19 & 0.20 & 0.17 & 0.19 & 0.03 \\
\hline & $(16.28)$ & $(7.10)$ & $(11.62)$ & $(3.82)$ & $(14.38)$ & $(6.52)$ & $(17.08)$ & $(1.88)$ \\
\hline \multirow[t]{2}{*}{ Market Beta } & -0.06 & -0.02 & -0.04 & 0.04 & -0.04 & -0.02 & -0.01 & 0.03 \\
\hline & $(-3.19)$ & $(-1.03)$ & $(-1.73)$ & $(1.58)$ & $(-2.63)$ & $(-1.13)$ & $(-0.31)$ & $(2.08)$ \\
\hline \multirow[t]{2}{*}{ Log Book Equity } & -0.46 & -0.18 & -0.45 & -0.23 & -0.43 & -0.20 & -0.23 & -0.09 \\
\hline & $(-36.12)$ & $(-8.39)$ & $(-12.82)$ & $(-6.54)$ & $(-47.96)$ & $(-16.28)$ & $(-12.25)$ & $(-9.52)$ \\
\hline Adj. $R^{2}$ & 0.54 & 0.33 & 0.70 & 0.52 & 0.61 & 0.38 & 0.42 & 0.28 \\
\hline Within Adj. $\mathrm{R}^{2}$ & 0.52 & 0.32 & 0.68 & 0.50 & 0.56 & 0.32 & 0.37 & 0.21 \\
\hline Observations & 8537 & 3090 & 1638 & 539 & 3027 & 1124 & 7100 & 2800 \\
\hline
\end{tabular}

Regressions of valuation ratios on firm-level characteristics for 4 regions. All regressions include year fixed effects. $m b$ is the $\log$ market-to-book ratio at time $t$. $e^{5}$ is cumulative earnings growth $t$ to $t+5$ adjusted for repurchases. Characteristics are measured at time $t$. Foreign sales is the fraction of sales from abroad, and Lerner is operating income after depreciation divided by sales, and market beta is 60-month rolling market beta where the market is the local MSCI index. Firm-level fundamentals are from FactSet from 2006 until 2016. 
Table 6

Demand Estimation Summary

\begin{tabular}{|c|c|c|c|c|c|c|c|c|c|}
\hline & Households & Inv. Large Passive & Inv. Small Passive & Inv. Small Active & Inv. Large Active & Hedge Funds & Long-Term & Private Banking & Brokers \\
\hline \multicolumn{10}{|c|}{ United States } \\
\hline Log Market-to-Book & -0.022 & 0.956 & 0.766 & 0.542 & 0.754 & 0.540 & 0.766 & 0.716 & 0.739 \\
\hline Foreign Sales & 0.133 & 0.014 & 0.033 & 0.022 & 0.025 & -0.037 & 0.002 & 0.065 & 0.010 \\
\hline Lerner & -0.017 & -0.003 & 0.021 & 0.035 & -0.001 & -0.029 & 0.041 & 0.042 & -0.024 \\
\hline Sales to Book & 0.189 & 0.027 & 0.043 & 0.002 & 0.038 & 0.023 & 0.045 & 0.057 & 0.068 \\
\hline Dividend to Book & 0.294 & -0.003 & 0.019 & -0.092 & -0.069 & -0.126 & 0.024 & 0.031 & 0.080 \\
\hline Market Beta & -0.073 & 0.003 & -0.012 & -0.026 & 0.018 & 0.027 & 0.020 & -0.057 & 0.057 \\
\hline Log Book Equity & 0.899 & 1.269 & 1.077 & 0.592 & 1.078 & 0.546 & 1.148 & 0.941 & 1.205 \\
\hline \multicolumn{10}{|c|}{ Great Britain } \\
\hline Log Market-to-Book & -0.457 & 0.663 & 0.805 & 0.700 & 0.709 & 0.745 & 0.707 & 0.768 & 0.689 \\
\hline Foreign Sales & 0.130 & 0.074 & 0.022 & 0.078 & 0.082 & -0.019 & 0.026 & -0.060 & -0.061 \\
\hline Lerner & 0.171 & -0.003 & -0.012 & -0.031 & -0.058 & 0.039 & 0.054 & -0.022 & 0.014 \\
\hline Sales to Book & 0.527 & 0.135 & 0.005 & 0.003 & 0.137 & 0.020 & 0.086 & 0.031 & 0.063 \\
\hline Dividend to Book & 0.327 & 0.082 & 0.036 & -0.026 & 0.028 & -0.122 & 0.024 & 0.036 & 0.025 \\
\hline Market Beta & 0.127 & -0.015 & -0.055 & -0.068 & -0.176 & -0.079 & -0.075 & -0.055 & -0.027 \\
\hline Log Book Equity & 0.642 & 1.214 & 1.168 & 0.928 & 1.071 & 0.840 & 1.258 & 1.152 & 1.148 \\
\hline \multicolumn{10}{|c|}{ Combined } \\
\hline Cross-Country & & 0.191 & 0.330 & 0.268 & 0.474 & 0.126 & 0.267 & 0.214 & 0.104 \\
\hline
\end{tabular}

Summary statistics of coefficient estimates from investor level demand system estimation in the United States and Great Britain. We report the weighted average of the parameter estimates for each investor in that group. To average the coefficients, we first compute the AUM-weighted average for a given investor group and year. We then average these across years for a given investor group. The cross-country coefficient is the estimate for the investor type. The household sector is constructed so that total holdings of a company add up to the company's market capitalization. Equity holdings data are from FactSet from 2006 until 2016. 
Table 7

Total repricing by investor type

\begin{tabular}{lrrrr}
\hline & & \multicolumn{3}{c}{ Repricing } \\
\cline { 3 - 5 } & Share AUM & Total & AUM Scaled & Unit Elasticity \\
\hline & United States & & \\
\hline Inv. Large Passive & 22.7 & 8.5 & 0.37 & 7.3 \\
Inv. Small Passive & 15.8 & 8.6 & 0.54 & 10.1 \\
Inv. Small Active & 16.8 & 22.3 & 1.33 & 18.6 \\
Inv. Large Active & 9.6 & 9.2 & 0.96 & 8.1 \\
Hedge Funds & 4.2 & 5.7 & 1.37 & 4.0 \\
Long-Term & 4.5 & 1.8 & 0.39 & 1.7 \\
Private Banking & 3.0 & 2.3 & 0.77 & 2.5 \\
Brokers & 1.2 & 0.9 & 0.75 & 0.8 \\
\hline & Great & Britain & & 9.7 \\
\hline Inv. Large Passive & 16.5 & 6.3 & 0.38 & 13.2 \\
Inv. Small Passive & 18.4 & 6.1 & 0.33 & 11.2 \\
Inv. Small Active & 10.3 & 6.7 & 0.64 & 7.1 \\
Inv. Large Active & 7.7 & 4.6 & 0.60 & 0.8 \\
Hedge Funds & 0.8 & 0.8 & 0.97 & 2.7 \\
Long-Term & 6.1 & 1.7 & 0.28 & 1.8 \\
Private Banking & 2.3 & 1.3 & 0.57 & 2.2 \\
Brokers & 2.8 & 1.5 & 0.55 &
\end{tabular}

Share AUM is the percent of assets under management for each investor type. Total repricing is the percent change in market cap if an investor type's demand changes to strict market weights. AUM scaled repricing is total repricing divided by the share of assets under management. Repricing with unit elasticity of demand is the percent change in market cap if an investor type's demand changes to strict market weights and assuming that the elasticity of demand is equal to 1 . Each value is the time series average of the yearly values. Firm-level fundamentals and equity holdings data are from FactSet from 2006 until 2016. 
Table 8

Largest Repricing by Individual Investors (United States, 2016)

\begin{tabular}{|c|c|c|c|c|}
\hline Type & Name & AUM (bn) & Active Share & Repricing (\%) \\
\hline \multirow[t]{4}{*}{ Inv. Large Active } & T. Rowe Price Associates, Inc. & 423 & 0.45 & 4.06 \\
\hline & Wellington Management Co. LLP & 324 & 0.41 & 2.80 \\
\hline & Capital Research \& Management Co. (Global Investors) & 250 & 0.44 & 2.46 \\
\hline & JPMorgan Investment Management, Inc. & 194 & 0.39 & 1.69 \\
\hline \multirow[t]{4}{*}{ Inv. Large Passive } & Fidelity Management \& Research Co. & 554 & 0.33 & 3.86 \\
\hline & The Vanguard Group, Inc. & 1,598 & 0.09 & 2.98 \\
\hline & Capital Research \& Management Co. (World Investors) & 328 & 0.37 & 2.78 \\
\hline & SSgA Funds Management, Inc. & 954 & 0.11 & 2.12 \\
\hline \multirow[t]{4}{*}{ Inv. Small Active } & PRIMECAP Management Co. & 84 & 0.56 & 1.02 \\
\hline & Jennison Associates LLC & 77 & 0.57 & 0.98 \\
\hline & ClearBridge Investments LLC & 75 & 0.50 & 0.86 \\
\hline & Janus Capital Management LLC & 68 & 0.59 & 0.86 \\
\hline \multirow[t]{4}{*}{ Inv. Small Passive } & American Century Investment Management, Inc. & 80 & 0.35 & 0.64 \\
\hline & State Farm Investment Management Corp. & 67 & 0.44 & 0.63 \\
\hline & Managed Account Advisors LLC & 94 & 0.31 & 0.62 \\
\hline & BlackRock Advisors LLC & 76 & 0.35 & 0.59 \\
\hline \multirow[t]{4}{*}{ Hedge Funds } & AQR Capital Management LLC & 62 & 0.45 & 0.59 \\
\hline & Millennium Management LLC & 38 & 0.51 & 0.35 \\
\hline & Citadel Advisors LLC & 30 & 0.57 & 0.35 \\
\hline & Renaissance Technologies LLC & 46 & 0.44 & 0.31 \\
\hline \multirow[t]{4}{*}{ Private Banking } & Goldman Sachs \& Co. LLC (Private Banking) & 99 & 0.28 & 0.58 \\
\hline & Wells Fargo Clearing Services LLC & 69 & 0.34 & 0.51 \\
\hline & Morgan Stanley Smith Barney LLC (Private Banking) & 86 & 0.26 & 0.51 \\
\hline & Bank of America, NA (Private Banking) & 68 & 0.27 & 0.41 \\
\hline \multirow[t]{4}{*}{ Long-Term } & Norges Bank Investment Management & 199 & 0.12 & 0.50 \\
\hline & APG Asset Management NV & 48 & 0.24 & 0.28 \\
\hline & Caisse de depot et placement du Quebec & 20 & 0.51 & 0.23 \\
\hline & PGGM Vermogensbeheer BV & 18 & 0.42 & 0.22 \\
\hline \multirow[t]{4}{*}{ Brokers } & Morgan Stanley \& Co. LLC & 50 & 0.34 & 0.31 \\
\hline & Credit Suisse Securities (USA) LLC (Broker) & 60 & 0.21 & 0.26 \\
\hline & Citigroup Global Markets, Inc. (Broker) & 21 & 0.39 & 0.15 \\
\hline & UBS Securities LLC & 16 & 0.41 & 0.12 \\
\hline
\end{tabular}

Top 4 investors within each type in terms of repricing. Repricing is calculated as percent change in market cap if that individual investor's demand changes to strict market weights. Firm-level fundamentals and equity holdings data are from FactSet from 2006 until 2016. 
Table 9

Change in Valuation Regression Coefficients

\begin{tabular}{|c|c|c|c|c|c|c|c|c|}
\hline & Inv. Large Passive & Inv. Small Passive & Inv. Small Active & Inv. Large Active & Hedge Funds & Long-Term & Private Banking & Brokers \\
\hline \multicolumn{9}{|c|}{ United States } \\
\hline Foreign Sales & -1.2 & 1.1 & -10.9 & -2.6 & 8.4 & 2.2 & -1.5 & 0.6 \\
\hline Lerner & 23.0 & 5.4 & -20.1 & 12.2 & 20.2 & -3.5 & -7.0 & 1.5 \\
\hline Sales to Book & 2.6 & 4.8 & 19.0 & 2.3 & -5.1 & 1.9 & -1.3 & -0.1 \\
\hline Dividend to Book & -0.8 & 1.4 & 63.7 & 15.3 & 22.8 & -1.8 & 1.8 & -0.6 \\
\hline Market Beta & -5.8 & -8.7 & -3.5 & -9.5 & -33.7 & -7.6 & 1.2 & -3.7 \\
\hline Log Book Equity & 2.2 & 8.0 & 48.0 & 4.2 & 10.9 & 0.2 & 2.6 & -0.1 \\
\hline R-squared & -1.9 & -5.0 & -16.3 & -1.8 & -4.9 & -1.8 & -1.2 & -0.2 \\
\hline \multicolumn{9}{|c|}{ Great Britain } \\
\hline Foreign Sales & -8.0 & 7.1 & -2.9 & 0.2 & 0.4 & 5.1 & 3.6 & 4.4 \\
\hline Lerner & 5.6 & 11.3 & 13.4 & 19.3 & -2.9 & -14.6 & 1.2 & 0.8 \\
\hline Sales to Book & -5.8 & 8.4 & 6.2 & -0.4 & -0.5 & -1.2 & -0.4 & 1.0 \\
\hline Dividend to Book & 3.3 & 2.5 & 5.1 & 0.6 & 0.8 & 3.4 & 0.4 & 0.3 \\
\hline Market Beta & -9.0 & 16.0 & 21.7 & 35.9 & 6.0 & 10.8 & 0.7 & -3.5 \\
\hline Log Book Equity & 4.7 & 11.6 & 12.1 & 6.2 & 1.4 & 0.8 & 1.1 & 1.5 \\
\hline R-squared & -2.2 & -4.2 & -3.2 & -3.2 & -0.4 & -0.6 & -0.4 & -0.6 \\
\hline
\end{tabular}

Percent change in regressions of valuation ratios on firm-level characteristics under each repricing scenario. Each column is the change in the coefficient from the actual valuation regression divided by the absolute value of the original regression coefficient and multiplied by 100. The new market-to-book ratios are calculated under the assumption that each investor type's demand changes to strict market weights. All regressions include year fixed effects. Characteristics are measured at time $t$. Foreign sales is the fraction of sales from abroad, and Lerner is operating income after depreciation divided by sales, and market beta is 60-month rolling market beta where the market is the local MSCI index. Firm-level fundamentals and equity holdings data are from FactSet from 2006 until 2016. 
Figure 2

Time series of ownership by institutional type.

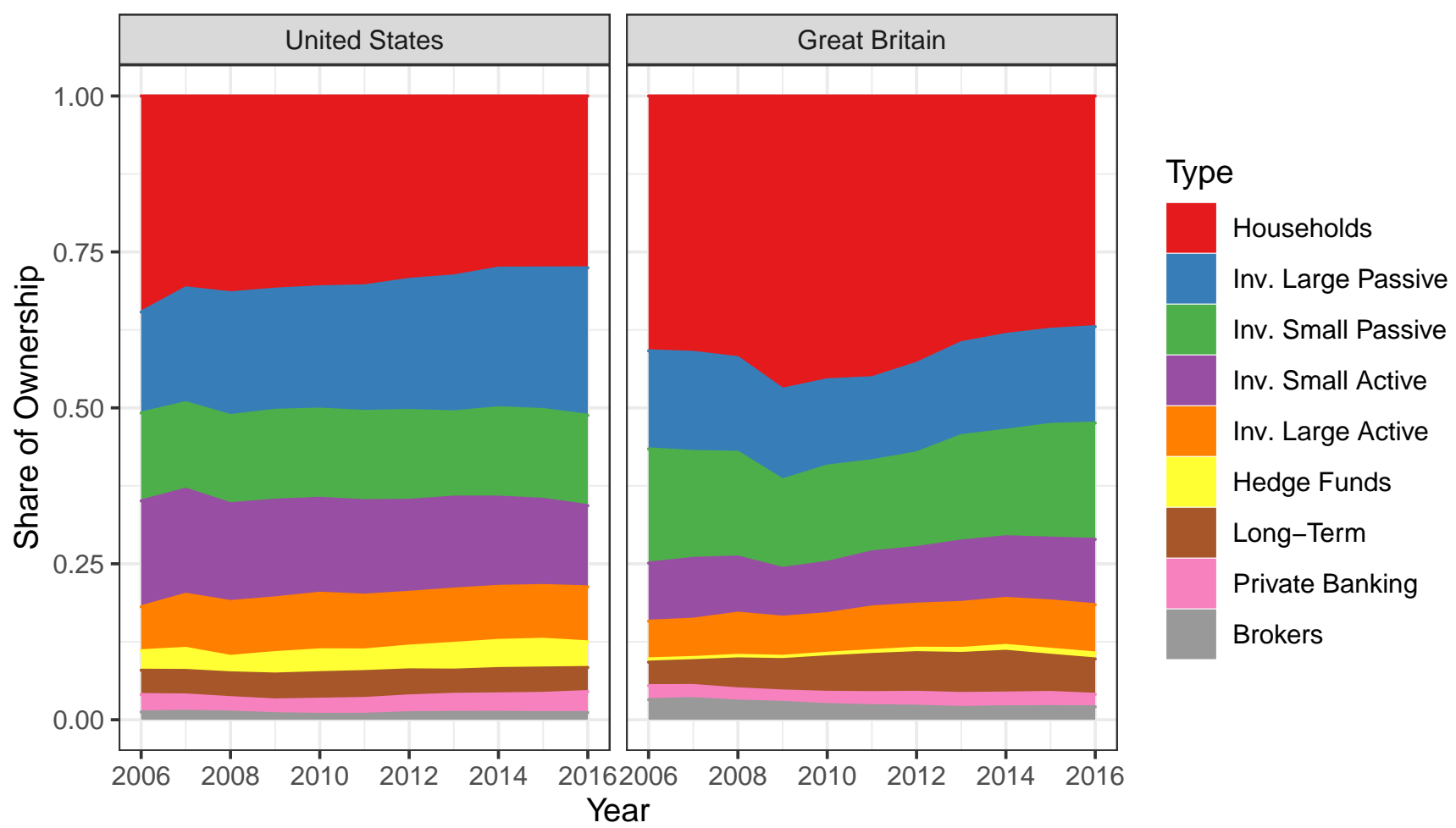

Share of total ownership by type of institution in the United States and Great Britain by year. Equity holdings data are from FactSet from 2006 until 2016. 
Figure 3

Demand Curve Summary by Investor Type (United States)
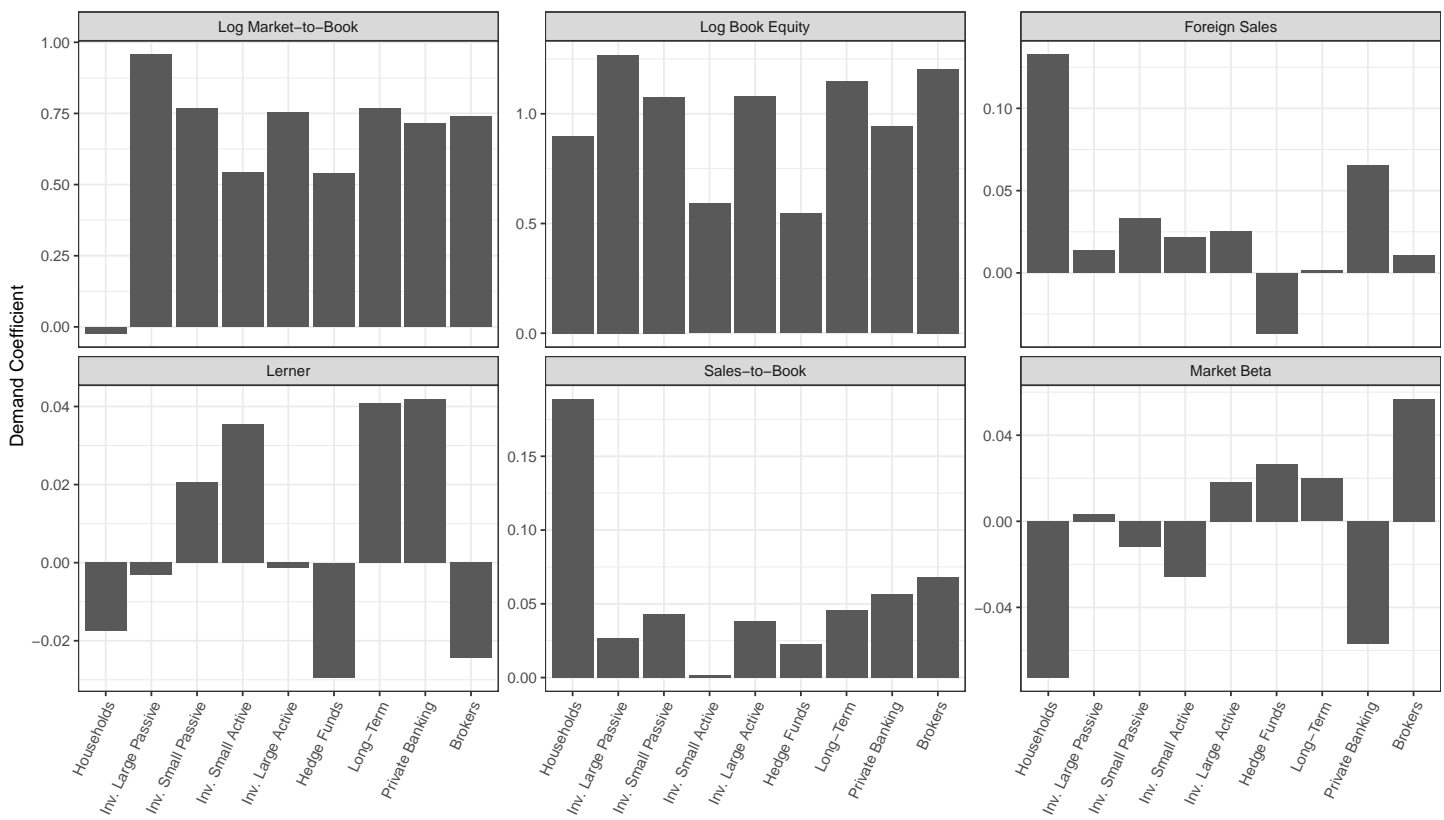

Summary of demand curves by investor type. We report the weighted average of the parameter estimates for each investor in that group. To average the coefficients, we first compute the AUM-weighted average for a given investor group and year. We then average these across years for a given investor group. Firm-level fundamentals and equity holdings data are from FactSet from 2006 until 2016. 
Figure 4

Total Repricing By Size (United States)

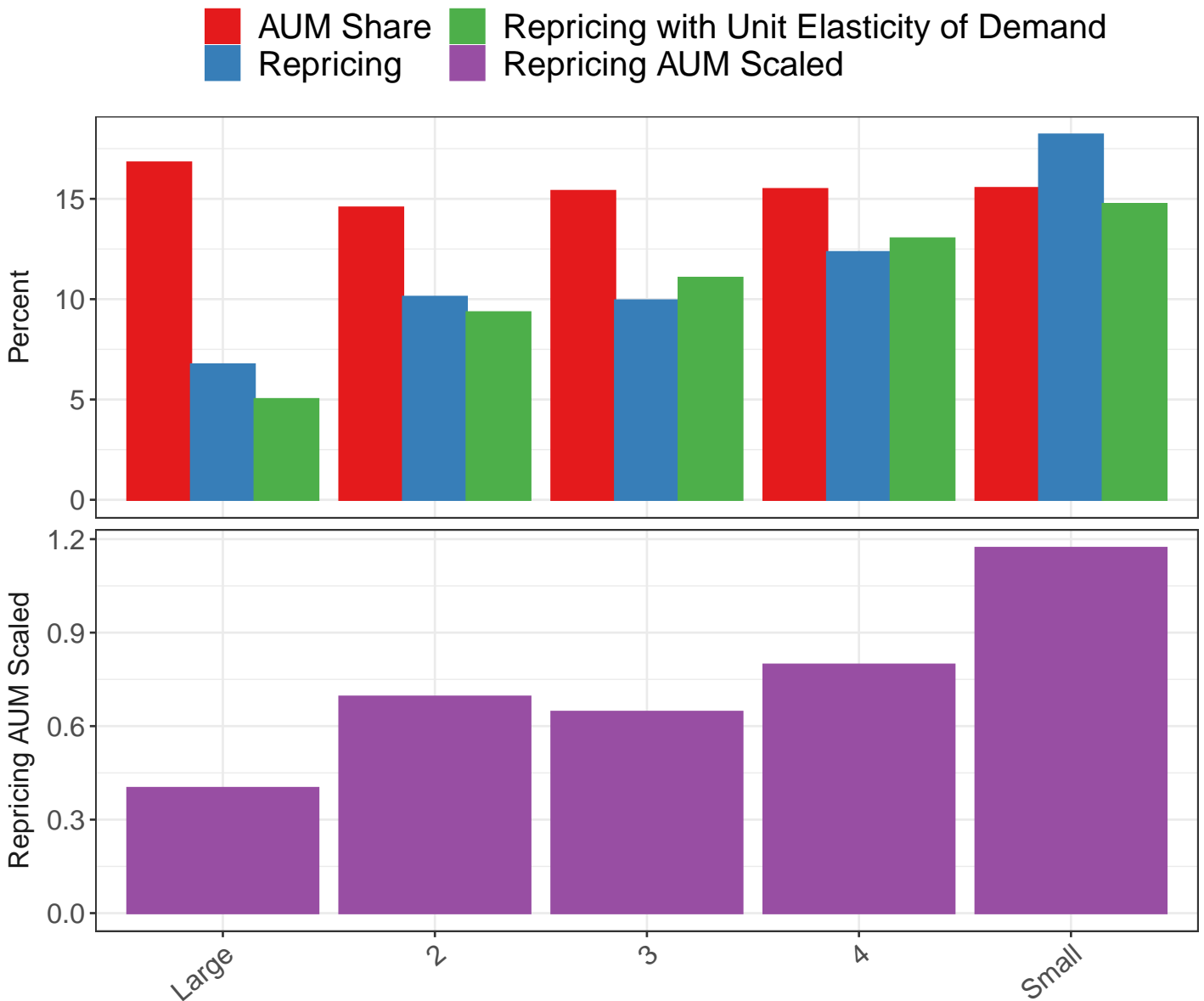

Size Decile

The top panel reports the fraction of assets under management, repricing, and repricing assuming that the elasticity of demand is 1 . Repricing is the percent change in market cap if a size group's demand changes to strict market weights. Repricing with unit elasticity of demand is the percent change in market cap if a size group's demand changes to strict market weights and assuming that the elasticity of demand is equal to 1 . The bottom panel reports the change in market cap normalized by the fraction of ownership. Each bar is the time series average of the yearly values. Firm-level fundamentals and equity holdings data are from FactSet from 2006 until 2016. 


\section{A. Data construction}

All FactSet data are from WRDS. We use FactSet fundamentals annual version 3 and FactSet ownership version 5. MSCI return indices are from DataStream. Interest rate data are from Global Financial Data.

We combine data from these sources to build an annual end-of-year panel of firm-level fundamentals and investor-level equity holdings from 2006 until 2016. Our fundamentals data covers 4 regions: United States (US), Euro Area (EA), Great Britain (GB), and Japan (JP). Our holdings data covers 2 regions: United States (US) and Great Britain (GB). EA consists of companies in Austria, Belgium, Finland, France, Germany, Ireland, Italy, Netherlands, Portugal, and Spain.

Market capitalization We combine monthly security prices and company-level shares outstanding from monthly_prices_final_usc and monthly_prices_final_int with point-in-time exchange rates from fx_rates_usd. We calculate company-level USD market cap using shares outstanding (ff_shs_out) times price (price_m) and convert to USD. Shares outstanding is the common shares outstanding at the company level. If a company has more than one share class, shares outstanding is adjusted for the relative par values of all share classes. Both prices and shares outstanding are adjusted for splits.

Some companies have many listed securities. To merge market caps with fundamentals, we select a unique primary security fsym_id for each company (factset_entity_id). We start from the set of securities which we can calculate a USD market cap for and merge on security and firm identifying information from sym_coverage and ff_sec_coverage. We sequentially select the first security for each company which is uniquely identified by the following criteria: one security for the company, ff_iscomp is 1 for the security, the security is identified as primary by fsym_primary_equity_id. If this procedure does not uniquely identify a primary security, we do not include the company in our sample. This occurs in a very small number of cases.

For each firm-year we use the market cap reported at the end of December.

Fundamentals Fundamentals are in 4 files for each of 3 regions: ff_FILE_REGION where FILE is one of basic_af, basic_der_af, advanced_af, advanced_der and REGION is one of ap, $\mathrm{eu}$, am. We merge these 12 files together with point-in-time exchange rates from fx_rates_usd and convert monetary values to USD. For fundamentals in December of each year we use the most recently available fundamentals as of the end of June of that year.

- Book equity is total shareholders equity (ff_shldrs_eq) plus deferred taxes and investment tax credits (ff_dfd_tax_itc) minus preferred stock (ff_pfd_stk). We set preferred stock to zero if it does not exist and drop negative book equity values.

- Market equity is total value of common equity as detailed in the market capitalization section above.

- Foreign sales share is international sales (ff_sales_intl) divided by total sales (ff_sales). 
- Lerner is operating income before depreciation (ff_oper_inc_bef_dep) minus depreciation and amortization (ff_dep_amort_exp) if available or operating income (ff_oper_inc) divided by sales (ff_sales).

- Sales to book is sales (ff_sales) divded by book equity

- Dividends to book are dividends (ff_div_cf) divided by book equity.

- Betas are from 60-month rolling regressions on MSCI local equity market index returns. Excess returns are calculated using 3-month rates from Global Financial data.

- Net repurchases are ff_stk_purch_cf minus ff_stk_sale_cf and are set to 0 if missing.

We winsorize beta at the 2.5\% and 97.5\% level and Winsorize dividend-to-book, and sales-to-book at the $97.5 \%$ level by region-year. We set values of Lerner that are less than -1 to -1 .

Portfolio Holdings We build a panel of end-of-year equity holdings of US and GB companies for institutional and non-institutional investors. FactSet collects data for global companies and institutions, but the coverage outside of the US and GB is not sufficient for our purposes of estimating a demand system. To remain consistent with FactSet's methodology we construct holdings data for all countries and then select holdings of only US and GB companies. We also limit our sample to 2006 until 2016 due to lower coverage in GB prior to 2006.

FactSet holdings data are from 4 broad sources:

- $13 \mathrm{~F}$ holdings $(13 \mathrm{~F}) .13 \mathrm{~F}$ data are from mandatory $13 \mathrm{~F}$ reports on US-traded equities held by institutions managing more than $\$ 100$ million in US-traded securities. Data is in own_inst_13f_detail_eq.

- Sum of fund-level reports (SOF). Fund-level data are from SEC mandated reports in the US and are collected directly from funds managers by FactSet in other countries. Data is in own_fund_detail_eq. Fund-level reports are aggregated to the institution level using the mapping from fund ids to institution ids in own_ent_funds.

- Institutional Stakes (INST). Institutional stakes data for GB and are sourced from share registers (UKSR) and regulatory news service filings (RNS). FactSet analyzes share registers at minimum annually, though for companies larger than fledgling the frequency is quarterly. Institutional stakes data for the US are sourced from regulatory filings such as 10K, 13D, 13G, and proxies. For other countries FactSet collects data from various regulatory filings. Data is in own_inst_stakes_detail_eq.

- Non-institutional stakes (NISTK). Non-institutional stakes are from regulatory filings and primarily represent holdings by firm insiders or by other companies. Data is in own_stakes_detail_eq. 
We combine data from the 4 sources. Securities are identified as either 13F US (fds_13f_flag=1), 13F Canada (fds_13f_ca_flag=1), or UKSR (fds_uksr_flag=1) in own_sec_coverage. Holder's are identified as $13 \mathrm{~F}$ institutions (fds_13f_flag=1) in own_ent_institutions. We use the following rules to combine institutional holdings as is done by FactSet:

- For UKSR securities, select UKSR or RNS positions (types W and Q) if the as_of_date is within 18 months of December of each year. If there are no intitutional stakes based filings for a given institution use SOF if the report is within 18 months of December of each year.

- For $13 \mathrm{~F}$ institutions and $13 \mathrm{~F}$ US securities, use the $13 \mathrm{~F}$ position if it is within 18 months of December of each year unless there is a more recent INST position.

- For $13 \mathrm{~F}$ institutions and $13 \mathrm{~F}$ CA securities, use the $13 \mathrm{~F}$ position if it is within 18 months of December of each year unless there is a more recent INST position. If there is are no $13 \mathrm{~F}$ or INST positions, use SOF if it is within 18 months of December of each year.

- For non-13F institutions and/or non-13F US/CA securities, use the INST position if it is within 18 months of December of each year for US securities and 21 month for non-US securities. If there is no INST position, use SOF if it is within 18 months of December of each year.

- Use NISTK positions if they are within 18 months of December of each year.

We merge on prices from own_sec_prices_eq and calculate dollar values of holdings for holdings of each security. We limit holdings to common equity and ADRs:

(fref_security_type=SHARE,ADR,DR,GDR,NVDR and issue_type=EQ in sym_coverage)

We aggregate dollar values of security-level holdings to company-level holdings using the mapping in own_sec_entity_eq.

We classify institutions into types using FactSet's investor_sub_type in sym_entity. Hedge Fund =AR, FH, FF, FU, FS; Broker=BM, IB, ST, MM; Private Banking=CP, FY, VC; Investment Advisor $=\mathrm{IC}, \mathrm{RE}, \mathrm{PP}, \mathrm{SB}, \mathrm{MF}$; Long-term $=\mathrm{FO}, \mathrm{SV}, \mathrm{IN}$;.

We construct the Household sector so that total holdings of institutions and household are equal to each firms market cap. On occasion, total holdings of institutions are great than the market cap, in which case we proportionally scale back all institutions holdings.

We split investment advisors into four groups. We first split investors into two groups of equal size. Within each size group, we split investors above and below the median active share. To have stable classifications across time, we collapse the classification across time and classify an investor as small (active) if it is assigned to a group more than half the periods. The active share is defined as the sum of the absolute value of the differences between the actual portfolio weights of an investor and a market-weighted portfolio based on the stocks held by the same investor, divided by two to avoid double-counting.

We classify the outside asset as any firm which is outside of the top $90 \%$ of market cap within each region. Any institution which has less that $\$ 1 \mathrm{~m}$ in holdings in the outside asset, is classified as a non-institutional stakes holder, or has less than 20 holdings across all years is moved into the household sector. 
Figure A.1

Comparison with IMF CPIS.

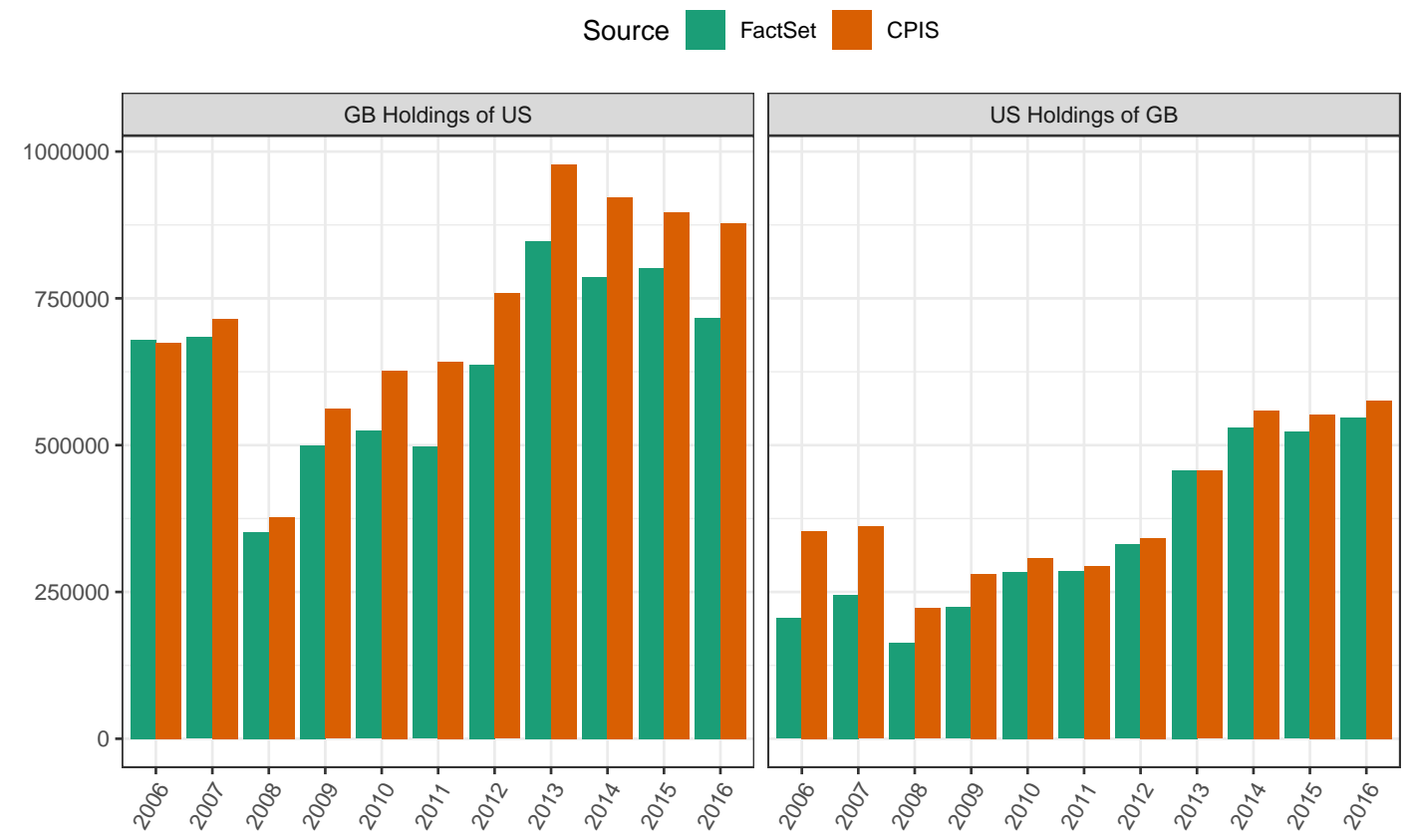

Total cross-border holdings of US and UK equities by US and UK investors. Equity holdings are from the IMF Coordinated Portfolio Investment Survey and FactSet from 2006 until 2016.

\section{B. Model derivations}

The first-order condition of investor $i$ is given by

$$
\left(\boldsymbol{g}_{i}-\boldsymbol{M} \boldsymbol{B}_{0}\right)-\gamma_{i}\left(\boldsymbol{\rho}_{i} \boldsymbol{\rho}_{i}^{\prime}+\sigma^{2} \boldsymbol{I}\right) \boldsymbol{Q}_{i}+y_{i}=0,
$$

implying

$$
\begin{aligned}
\boldsymbol{Q}_{i} & =\frac{1}{\gamma_{i}}\left(\boldsymbol{\rho}_{i} \boldsymbol{\rho}_{i}^{\prime}+\sigma^{2} \boldsymbol{I}\right)^{-1}\left(\boldsymbol{g}_{i}-\boldsymbol{M} \boldsymbol{B}_{0}+y_{i}\right) \\
& =\frac{1}{\gamma_{i} \sigma^{2}}\left(\boldsymbol{I}-\frac{\boldsymbol{\rho}_{i} \boldsymbol{\rho}_{i}^{\prime}}{\boldsymbol{\rho}_{i}^{\prime} \boldsymbol{\rho}_{i}+\sigma^{2}}\right)\left(\boldsymbol{g}_{i}-\boldsymbol{M} \boldsymbol{B}_{0}+y_{i}\right) \\
& =\frac{1}{\gamma_{i} \sigma^{2}}\left(\boldsymbol{g}_{i}-\boldsymbol{M} \boldsymbol{B}_{0}+y_{i}\right)-\frac{c_{i}}{\gamma_{i} \sigma^{2}} \boldsymbol{\rho}_{i}
\end{aligned}
$$

where $c_{i}=\left(\boldsymbol{\rho}_{i}^{\prime} \boldsymbol{\rho}_{i}+\sigma^{2}\right)^{-1} \boldsymbol{\rho}_{i}^{\prime}\left(\boldsymbol{g}_{i}-\boldsymbol{M} \boldsymbol{B}_{0}+y_{i}\right)$ is a scalar that is common across all stocks. Hence, an investor's demand for a given stock depends on its expected return (that is, the expected growth rate of fundamentals relative to the stock's current valuation), its riskiness, and the hedging benefit it provides. By substituting the assumptions that we made about 
expected growth rates and the stocks' riskiness in (4), (5), and (6) we obtain

$\boldsymbol{Q}_{i}(n)=-\frac{1}{\gamma_{i} \sigma^{2}} \boldsymbol{M} \boldsymbol{B}_{0}(n)+\frac{1}{\gamma_{i} \sigma^{2}}\left(\boldsymbol{\lambda}_{i}^{g}-c_{i} \boldsymbol{\lambda}_{i}^{\rho}+\boldsymbol{\lambda}_{i}^{Y}\right)^{\prime} \boldsymbol{x}(n)+\frac{1}{\gamma_{i} \sigma^{2}}\left(\nu_{i}^{g}(n)-c_{i} \nu_{i}^{\beta}(n)+\nu_{i}^{Y}(n)\right)$,

which is the expression announced in (7).

By aggregating investors' demands and equating to supply, we solve for equilibrium asset prices,

$$
\sum_{i} \boldsymbol{Q}_{i}=\boldsymbol{B}
$$

where we use that the supply of each stock is normalized to one and $Q_{i}(n)=B(n) q_{i}(n)$. This implies

$-\sum_{i} \frac{1}{\gamma_{i} \sigma^{2}} M B(n)+\sum_{i} \frac{1}{\gamma_{i} \sigma^{2}}\left(\boldsymbol{\lambda}_{i}^{g}-c_{i} \boldsymbol{\lambda}_{i}^{\rho}+\boldsymbol{\lambda}_{i}^{Y}\right)^{\prime} x(n)+\sum_{i} \frac{1}{\gamma_{i} \sigma^{2}}\left(\nu_{i}^{g}(n)-c_{i} \nu_{i}^{\rho}(n)+\nu_{i}^{Y}(n)\right)=B(n)$,

that is,

$$
M B(n)=\left(\sum_{i} m_{i} \boldsymbol{\beta}_{1 i}\right)^{\prime} \boldsymbol{x}(n)+\sum_{i} m_{i} \epsilon_{i}(n)-\sigma^{2}\left(\frac{B(n)}{\sum_{i} \tau_{i} A_{i}}\right) .
$$

where $\boldsymbol{\beta}_{1 i}=\boldsymbol{\lambda}_{i}^{g}-c_{i} \boldsymbol{\lambda}_{i}^{\rho}+\boldsymbol{\lambda}_{i}^{Y}, \epsilon_{i}(n)=\nu_{i}^{g}(n)-c_{i} \nu_{i}^{\beta}(n)+\nu_{i}^{Y}(n)$, and

$$
m_{i}=\frac{\gamma_{i}^{-1}}{\sum_{j} \gamma_{j}^{-1}}=\frac{\tau_{i} A_{i}}{\sum_{j} \tau_{j} A_{j}}
$$

given our assumption that $\gamma_{i}=\left(\tau_{i} A_{i}\right)^{-1}$.

\section{Numerical algorithm to compute the ridge estimator}

We start from

$$
\mathbb{E}_{t}\left[\left(\delta_{i, t}(n) \exp \left\{-\boldsymbol{\beta}_{i}^{\prime} \boldsymbol{X}_{t}(n)\right\}-1\right) Z_{t}(n)\right]-D\left(\boldsymbol{\Lambda}_{i}\right)\left(\boldsymbol{\beta}_{i}-\boldsymbol{\beta}^{T}\right)=0 .
$$

where $\delta_{i, t}(n)=\frac{w_{i, t}(n)}{w_{i, t}(0)}$. We start from an initial estimate, $\boldsymbol{\beta}_{i}^{(1)}$, which we discuss below. We then use a first-order Taylor expansion of the moment conditions around $\boldsymbol{\beta}_{i}^{(1)}$ to find $\boldsymbol{\beta}_{i}^{(2)}$

$$
\begin{aligned}
& \mathbb{E}_{t}\left[\left(\delta_{i, t}(n) \exp \left\{-\boldsymbol{\beta}_{i}^{(1) \prime} \boldsymbol{X}_{t}(n)\right\}-1\right) Z_{t}(n)\right]-D\left(\boldsymbol{\Lambda}_{i}\right)\left(\boldsymbol{\beta}_{i}^{(1)}-\boldsymbol{\beta}^{T}\right)- \\
& {\left[\mathbb{E}_{t}\left[\delta_{i, t}(n) \exp \left\{-\boldsymbol{\beta}_{i}^{(1) \prime} \boldsymbol{X}_{t}(n)\right\} Z_{t}(n) \boldsymbol{X}_{t}(n)^{\prime}\right]+D\left(\boldsymbol{\Lambda}_{i}\right)\right]\left(\boldsymbol{\beta}_{i}^{(2)}-\boldsymbol{\beta}_{i}^{(1)}\right) } \\
= & 0,
\end{aligned}
$$


implying

$$
\begin{aligned}
\boldsymbol{\beta}_{i}^{(2)}= & \boldsymbol{\beta}_{i}^{(1)}+\left[\mathbb{E}_{t}\left[\delta_{i, t}(n) \exp \left\{-\boldsymbol{\beta}_{i}^{(1) \prime} \boldsymbol{X}_{t}(n)\right\} Z_{t}(n) \boldsymbol{X}_{t}(n)^{\prime}\right]+D\left(\boldsymbol{\Lambda}_{i}\right)\right]^{-1} \times \\
& {\left[\mathbb{E}_{t}\left[\left(\delta_{i, t}(n) \exp \left\{-\boldsymbol{\beta}_{i}^{(1) \prime} \boldsymbol{X}_{t}(n)\right\}-1\right) Z_{t}(n)\right]-D\left(\boldsymbol{\Lambda}_{i}\right)\left(\boldsymbol{\beta}_{i}^{(1)}-\boldsymbol{\beta}^{T}\right)\right] . }
\end{aligned}
$$

We iterate on this procedure until convergence. Note that the numerator of the adjustment term are the moment conditions in (33), implying that upon convergence, the moment conditions are satisfied. For numerical stability, we limit the updating step for each of the coefficients to 1 or -1 .

To obtain the initial estimate, $\boldsymbol{\beta}_{i}^{(1)}$, we omit the zero holdings and use the linear moment conditions

$$
\mathbb{E}_{t}\left[\left(\ln \delta_{i, t}(n)-\boldsymbol{\beta}_{i}^{(1) \prime} \boldsymbol{X}_{t}(n)\right) Z_{t}(n)\right]-D\left(\boldsymbol{\Lambda}_{i}\right)\left(\boldsymbol{\beta}_{i}^{(1)}-\boldsymbol{\beta}^{T}\right)=0
$$

implying

$$
\boldsymbol{\beta}_{i}^{(1)}=\left[\mathbb{E}\left[Z_{t}(n) \boldsymbol{X}_{t}(n)^{\prime}\right]+D\left(\boldsymbol{\Lambda}_{i}\right)\right]^{-1}\left[\mathbb{E}_{t}\left[Z_{t}(n) \ln \delta_{i, t}(n)\right]+D\left(\boldsymbol{\Lambda}_{i}\right) \boldsymbol{\beta}^{T}\right] .
$$

\section{Variance decompositions using characteristics}

We show how our valuation regressions and earnings predictability regressions connect to traditional variance decompositions. Starting from (25) without expectations, it holds

$$
m b_{t}(n)=c+\sum_{s=1}^{\infty} \rho^{s-1} e_{t+s}(n)-\sum_{s=1}^{\infty} \rho^{s-1} r_{t+s}(n) \text {. }
$$

Consider a linear projection of both sides on a set of characteristics, $x_{t}(n)$ as well as a time fixed effect, which yields

$$
a_{m b, t}+\lambda_{m b}^{\prime} x_{t}(n)=a_{e, t}+\lambda_{e}^{\prime} x_{t}(n)-\left(a_{r, t}+\lambda_{r}^{\prime} x_{t}(n)\right),
$$

implying

$$
\begin{aligned}
a_{m b, t} & =a_{e, t}-a_{r, t}, \\
\lambda_{m b} & =\lambda_{e}-\lambda_{r} .
\end{aligned}
$$

Hence, the fraction of market-to-book ratios that can be explained by characteristics, $\operatorname{Var}\left(\lambda_{m b}^{\prime} x_{t}(n)\right)$, satisfies the variance decomposition

$$
\operatorname{Var}\left(\lambda_{m b}^{\prime} x_{t}(n)\right)=\operatorname{Cov}\left(\lambda_{m b}^{\prime} x_{t}(n), \lambda_{e}^{\prime} x_{t}(n)\right)-\operatorname{Cov}\left(\lambda_{m b}^{\prime} x_{t}(n), \lambda_{r}^{\prime} x_{t}(n)\right)
$$


and the fraction due to returns therefore equals

$$
\text { Fraction due to expected returns }=\frac{\lambda_{m b}^{\prime} \Sigma_{x}\left(\lambda_{m b}-\lambda_{e}\right)}{\lambda_{m b}^{\prime} \Sigma_{x} \lambda_{m b}},
$$

and the fraction due to expected growth rates

$$
\text { Fraction due to expected growth rates }=\frac{\lambda_{m b}^{\prime} \Sigma_{x} \lambda_{e}}{\lambda_{m b}^{\prime} \Sigma_{x} \lambda_{m b}},
$$

with $\Sigma_{x}=\operatorname{Var}\left(\Sigma_{x}\right)$. As characteristics are cross-sectionally standardized, if the characteristics are also uncorrelated, then the shares equal $\frac{\lambda_{m b}^{\prime}\left(\lambda_{m b}-\lambda_{e}\right)}{\lambda_{m b}^{\prime} \lambda_{m b}}$ and $\frac{\lambda_{m b}^{\prime} \lambda_{e}}{\lambda_{m b}^{\prime} \lambda_{m b}}$, respectively. 